\title{
América Latina y el Sistema Internacional en la década del ochenta ¿Hacia un nuevo orden antártico?
}

\section{INTRODUCGIÓN}

En 1959 se firma el Tratado Antártico (TA) por doce países (Cuadro 1). En este conjunto (Cuadros 1 y 2) coexistirán con dificultad los encontrados intereses de estados que ya presentaban una sostenida actividad antártica de varias décadas en defensa de sus reclamos de soberanía sobre sectores de la misma: las superpotencias, que si bien no efectúan reclamos (pero sí se reservan el derecho a hacerlo en el futuro), tampoco aceptan los de las restantes naciones y de un grupo de países invitados a participar por haber actuado allí durante el Año Geofísico Internacional.

El propósito del Tratado es el de asegurar la libertad de investigación científica y la cooperación internacional con ese objeto y el uso pacífico de la Antártida. Se prohíbe expresamente toda medida de carácter militar, las explosiones nucleares y la eliminación de desechos radiactivos en una región que comprende al Continente y a las aguas situadas al sur del paralelo $60^{\circ}$ de latitud sur (incluyendo las barreras de hielo). Se establece un sistema de inspección por parte de los países miembros para verificar su cumplimiento y un mecanismo de intercambio de información y de consulta mutua (Las Reuniones Consultivas) sobre asuntos de interés común relacionados con el Continente (Art. IX).

A través de esas consultas se recomiendan a los Gobiernos las medidas que se consideran adecuadas para promover los objetivos y principios del Tratado. Entre ellas, además de las ya nombradas, se encuentran las cuestiones relacionadas con el ejercicio de jurisdicción y la protección y conservación de los recursos antárticos vivos. Por último, el Tratado se halla abierto a la adhesión de otros estados, pero para obtener el estatus de "parte consultante" se deben satisfacer ciertos requisitos.

En 1979 se realiza en Washington la Décima Reunión Consultiva de los miembros del TA. En los veinte años transcurridos varias naciones han adherido a él y una se ha convertido en miembro 


\section{Cuadro 1}

TRATADO ANTARTICO: ESTATUS DE SUS MIEMBROS

\begin{tabular}{ll}
\hline \multicolumn{1}{c}{ Miembros Consultivos } & \multicolumn{1}{c}{ Miembros Adherentes* $^{*}$} \\
\hline Argentina & Holanda (1967) \\
Australia & Checoslovaquia (1962) \\
Bélgica & Dinamarca (1965) \\
Chile & Brasil (1976) \\
EE. uU. & Rumania (1971) \\
URss & Rep. Dem. Alemana (1971) \\
Polonia & Rep. Federal Alemana (1978) \\
Japón & \\
Nueva Zelandia & \\
Noruega & \\
Francia & \\
Rep. Sudafricana & \\
Gran Bretaña & \\
\hline
\end{tabular}

*Año de adhesión.

Cuadro 2

TRATADO ANTARTICO: PAISES GON RECLAMOS TERRITORIALES PREVIOS A LA FIRMA DEL TRATADO

\begin{tabular}{lll} 
& Argentina & Noruega \\
Australia & Inglaterra \\
Chile & Francia \\
& Nueva Zelandia \\
\hline
\end{tabular}

consultivo (Polonia; cuadro 1). Los principales objetivos políticos de los EE. UU. y otras grandes potencias que condujeron a la firma del Tratado-evitar que el Continente fuera incluido en el juego de la "guerra fría" entre la uRss y los EE. UU.; avanzar hacia formas de internacionalización limitada del Continente y obtener una fórmula de compromiso entre naciones reclamantes y no-reclamantes que permitiera el libre acceso de los miembros del acuerdo a toda la Antártida, "congelando" temporalmente Ios problemas de soberanía- continúan vigentes, pero su concreción se halla amenazada por los importantes cambios que se sucedieron en el sistema mundial. Además del agregado de otros miembros, el grupo de estados que origina el TA debe enfrentar una amplia gama de problemas, para muchos de los cuales el Tratado no se halla debida- 
mente preparado: entre ellos un incremento de los conflictos vinculados a los reclamos territoriales y a la competencia estratégica; la aparición de recursos naturales de gran importancia y de actores externos (empresas transnacionales, organismos internacionales y países en desarrollo) con crecientes y divergentes intereses en el Continente y sus espacios adyacentes. He aquí algunos ejemplos.

\section{Cuadro $\$$}

TRATADO ANTARTICO: PAISES QUE HAN MANIFESTADO EN FORMA NO OFICIAL INTERES EN PRESENTAR RECLAMOS TERRITORIALES

\begin{tabular}{ll} 
Brasil & Uruguay \\
Bélgica & Perú \\
& Colombia \\
\hline
\end{tabular}

Guadro 4

PAISES GON FLOTAS PESQUERAS DE ALTA MAR

(para aguas distantes)

$\begin{array}{ll}\text { Australia } & \text { Francia } \\ \text { EE. uv. } & \text { Polonia } \\ \text { Japón } & \text { Noruega } \\ \text { URss } & \text { Bélgica } \\ & \text { Rep. Democrática Alemana } \\ & \text { Inglaterra }\end{array}$

FuENTE: Según datos extrafdos del Lloy's Register of Shipping: Statistical Tables.

A fines de 1978 Chile y Argentina se hallaron al borde de un serio conflicto en virtud de las respectivas aceptación y rechazo de los resultados de un laudo arbitral sobre la denominada "cuestión del Beagle". Especialistas y prensa en ambos países se refieren a la importancia que el resultado de dicho laudo puede asumir como instrumento político-jurídico ${ }^{1}$ capaz de fortalecer o deteriorar, según sea el caso, las posiciones que las dos naciones mantienen con

${ }^{1}$ Entre los innumerables artf́culos disponibles, ver, por ejemplo, "Acto Ilegal en el Sur", por J. Mendoza Bahiamonde, Revista de Armas y Servicios del Ejercito No 13, 1978, Santiago, Chile, y "Acto Ilegal en el Sur", Clarin, Buenos Aires, 11-6-78. 
respecto a sus reclamos de soberanía sobre sectores antárticos que en parte se superponen ${ }^{2}$.

En 1975, en sesiones del Subcomité de Océano y Medio Ambiente del Senado de los EE. UU., el Senador Pell sugiere que la industria privada -en particular, la vinculada a minerales pesados y petróleo- integre la delegación oficial norteamericana a las Reuniones Consultivas del Tratado Antártico. En el interín el Jefe del Departamento de Recursos Energéticos de la Oficina de Investigación Geológica de los $\mathrm{xE.} \mathrm{UU.} \mathrm{aclara} \mathrm{que} \mathrm{las} \mathrm{reservas} \mathrm{recupera-}$ bles de petróleo en la Aritártida se estiman en el orden de los quince mil millones ${ }^{3}$ de barriles.

Intentos hechos por agencias de las Naciones Unidas para participar en alguna de las actividades contempladas en el Tratado (ej.: protección del ambiente; explotación de los recursos vivos del Océano Sur) no han sido bien recibidos por las partes contratantes, que se han opuesto - hasta el presente, con eficacia- a toda intervención ${ }^{4}$.

Idéntica actitud ha sido adoptada por los miembros del Tratado frente a toda acción destinada a vincular directa o indirectamente al Nuevo Derecho del Mar (NDM) con la cuestión antártica. Varios intentos han surgido por parte de algunos países en desarrollo (por ejemplo, las naciones árabes, en 1976; Brasil, en 1979) de incorporar la "cuestión antártica" al temario de la conferencia del NDM, argumentando que a la Antártida le debe ser aplicado un régimen de "Patrimonio Común de la Humanidad"s,

Evaluando los intereses estratégicos de la Unión Soviética frente a restricciones que impondrá al uso militar de los océanos el NDM, un experto en polftica y estrategia marítima norteamericana (Mongone, 1978 ,p.: 69), afirma que: "Ningún Tratado de Derecho del Mar podrá en el largo plazo negar a la Unión Soviética o a los EE. UU. la utilización de los océanos para satisfacer sus necesidades vitales de seguridad"... ..." "para IOS EE. UU. en particular, el control del Océano que le permita apoyar a sus aliados y

'Entre los meridianos 53' y 74' de longitud Oeste a partir del Polo sur se ejerce jurisdicción conjunta entre Chile y Argentina sobre ese Sector Antártico. (Ver: "Declaraciones Conjuntas Argentino-Chilenas", años 1947, 1948 y 1974). 1975.

"Estimating the Antartic Oil Resources", The -Washington Post, March 12,

"Sollie, F. "Regimes for living and Mineral Resources in the Antartic", Law of the Sea: Neglected Issues. Proceedings of the Sea Institute, XIr Annual Conference. Edited by J. King Gamble, The Hague, Netherlands, 1979, p. 205. (Sollie opina sin embargo que se exagera esa predisposición negativa). Sobre la posición de los EE. vU. ver Hearings, 1975.

${ }^{5}$ Conversaciones de carácter confidencial mantenidas con miembros de delegaciones nacionales que tomaron parte en las reuniones de la conferencia del Derecho del Mar. 
proteger el comercio internacional, incluyendo el acceso de la crucial provisión de petróleo, no podrá ser abandonado por artículos legales solamente aprobados por los países en desarrollo de Asia, Africa y América Latina".

Por su parte el máximo estratega naval soviético, Almirante Gorshkov, Comandante en Jefe de la Armada, expuso claramente ${ }^{6}$ las misiones que debía satisfacer esa fuerza en el despliegue de la competencia global con los EE. UU. En particular, se destaca el papel que se le asigna a la marina como un instrumento de la polftica exterior destinado a demostrarle a los Estados Unidos que ya no posee el dominio de los mares y la importancia creciente que merece en la política de la uRss el estar presente en todos los océanos donde posee intereses estratégicos ${ }^{7}$.

Los hechos aquí citados sólo presentan algunos de los aspectos conflictivos vinculados a la creciente importancia que adquiere el continente antártico en varias dimensiones: a) el sistema internacional global; b) el subsistema regional latinoamericano y c) el subsistema antártico propiamente dicho. En este contexto, los problemas relativos a los aspectos de seguridad y estrategia; la exploración, explotación y conservación de los recursos oceánicos y continentales y la cuestión de los reclamos de soberanía sobre vastas porciones del territorio constituyen temas que atraen cada día mayor atención por parte de actores nacionales, internacionales y transnacionales. La Antártida entra en consecuencia a formar parte en forma decidida del conjunto de problemas relevantes que deben enfrentar estos actores, constituyéndose por propia gravitación en un nuevo y activo subsistema del sistema internacional.

No obstante la literatura disponible, de por sí escasa, si se considera la magnitud y urgencia de los problemas existentes, tiende a ofrecer un tratamiento temático sectorial que carece en muchas ocasiones del marco conceptual global donde ellos se hallan insertos. Otra limitación que surge de estos enfoques es la ausencia o el insuficiente análisis de las interacciones entre los distintos:conjuntos de factores.

Estas omisiones resultan particularmente significativas, ya que dificultan el obtener una percepción realista de los conflictos y posibilidades de cooperación existentes, así como los límites concre-

'Ver entre otras fuentes, Naves en Guerra y en la Paz, colección de artículos suyos publicados en inglés por United States Naval Institution, Ed. Herbert Preston.

'Moneta, C.: La Estrategia Naval Soviética en el Indico y Atlántico Sur: Algunas consideraciones. Apuntes de Clase, Universidad del Salvador, Facultad de Ciencias Polfticas y Sociales, Curso de Política Internacional, 1968-69, y ponencia sobre el tema presentada al "Primer Congreso Nacional de Geopolftica", Universidad Nacional de Mendoza, agosto 1974. 
tos que surgen para la actividad de los actores y las alternativas políticas viables a su alcance.

Intentando tener en cuenta estos aspectos, el presente trabajo pretende aportar algunas consideraciones sobre los problemas relacionados con el surgimiento y las características de un "Nuevo Orden Antártico" a que daría lugar en los próximos años la interacción de factores políticos, estratégicos, económicos, científicos y tecnológicos que ya se hallan actuando intensamente dentro y fuera del marco del TA.

\section{TENDENGIAS DEL RÉGIMEN INTERNAGIONAL Y SUS EFEGTOS SOBRE LA ANTÁRTICA}

Sin pretender desarrollar el tema, la identificación de las tendencias principales del régimen internacional facilita visualizar las interacciones de los problemas antárticos con el resto del conjunto global. En efecto, se presentan ya todos los elementos necesarios para considerar a Ia Antártida como un subsistema del sistema mundial. Se cuenta con actores estables (los países participantes en el $\mathrm{TA}$ ), reglas de juego y pautas de interacción identificables y regulares que caracterizan y diferencian al subsistema de su ambiente externo, así como límites definidos (régimen del tratado, mecanismos operativos, etc.). Asimismo, se han producido impactos provenientes del marco externo que por su naturaleza e importancia (Fj.: búsqueda de nuevas fuentes de petróleo y gas, NDM, etc.) comienzan a afectar significativamente al subsistema antártico, enfrentándolo con la. necesidad de introducir cambios y adaptaciones profundas para lograr su mantenimiento.

De igual manera, factores de tensión y conflicto interno preexistentes (Ej.: la "congelación" de los reclamos de soberanía territorial y consecuentemente el deseo de evitar en lo posible el tratamiento de los problemas de conservación y explotación de los recursos naturales) han sido enérgicamente activados en función de los problemas que enfrenta el conjunto mundial.

Resulta entonces conveniente identificar cuáles son las tendencias y factores que presenta dicho sistema y que afectan seriamente al actual régimen antártico:

\section{Tendencias observables a nivel global}

a) "Estado de flujo" del sistema internacional. Búsqueda de un "Nuevo Orden Internacional". Existencia de modelos contrapuestos que se proponen para el régimen mundial, según los intereses de los diferentes actores. 
b) Mantenimiento de la competencia estratégica EE. UU.-URss en su presente orientación de "acuerdos selectivos" y articulación de reglas de juego para la obtención del predominio: .....

c) Creciente importancia del enfrentamiento entre países desarrollados y en desarrollo, ante el intento de estos últimos de modificar las presentes relaciones de poder a través de una redistribución de los recursos políticos, económicos, tecnológicos, científicos, militares y culturales.

d) Revalorización conflictiva de los recursos naturales, en particular los energéticos.

e) Universalización e interdependencia del sistema global. Desde el punto de vista geográfico y del uso de los recursos, significa: 1) la incorporación del Océano como nuevo territorio que se integra en forma total a la dinámica del sistema; 2) la incorporación gradual de la Antártida a dicho sistema.

f) Greciente "transnacionalización" del sistema. Actores Transnacionales (Ej.: Empresas Transnacionales) adquieren mayor capacidad para imponer sus intereses vis-a-vis los actores nacionales.

g) EI notable incremento de la influencia que ejerce la disposición de recursos científicos y tecnológicos sobre las capacidades $y^{\prime}$ modalidades de acción de los actores nacionales, internacionales y transnacionales.

h) La gradual modificación de los criterios geopolíticos y estratégicos. tradicionales a la luz de los cambios cualitativos y cuantitativos que se registran en diversos dominios.

Gada una de las tendencias señaladas ejerce significativa influencia sobre los temas antárticos y se expresará en distintos campos (Ej.: Jurídico, estratégico, económico, etc.). El subsistema antártico no puede escapar entonces en la búsqueda de soluciones a sus problemas, a las indeterminaciones y condicionamientos transmitidos por el "estado de transición" del sistema mundial. A su vez presenta la oportunidad de servir de modelo para el futuro, aportando nuevas propuestas y modalidades de acomodación de intereses contrapuestos. En ello precisamente radica en gran parte el interés por su estudio, ya que se trata de un caso que presenta varios problemas sustantivos de los enfrentamientos Este-Oeste y NorteSur, que es dable esperar en la década del ochenta. 


\section{Gondicionamientos del subsistema antártico}

Teniendo en cuenta las interacciones existentes, se puede señalar:

-El enfrentamiento así como los conflictos Sur-Sur y Norte-Sur obligan a considerar los aspectos estratégicos de seguridad en la Antártida y sus zonas de influencia.

- Las tensiones Norte-Sur señalan la importancia de:

1) La tendencia a la universalización de la participación de los actores nacionales, internacionales y transnacionales frente al "régimen de alta exclusividad" que presenta el TA: es decir, los problemas que deberán enfrentar los miembros del Tratado en su conjunto, frente a los intereses del resto de la comunidad internacional.

2) Dado que el Subsistema antártico contiene a actores desarrollados y en desarrollo, en su seno se reproducen las situaciones de enfrentamiento que caracterizan al sistema mundial. La revalorización de los recursos naturales, particularmente petróleo y gas, y el problema de las jurisdicciones nacionales, constituirán temas esenciales en este sentido.

3) La competencia entre varios modelos de un nuevo orden internacional conduce a tener en cuenta - entre otros factores- cuáles son las formas de inserción al sistema global de los países latinoamericanos miembros del tratado y sus posibles efectos sobre las posiciones adoptadas frente a los problemas antárticos.

En particular:

- Frente a la expansión de la actividad humana y sus efectos sobre el sistema global, la incorporación de los nuevos territorios oceánicos y antárticos impone la necesidad de analizar su futuro régimen dado que: 1) el Hemisferio Sur es predominantemente marítimo; 2) la Antártida se encuentra rodeada de vastas masas de agua que la separan de los restantes continentes; 3) el régimen jurídico a aplicarse en "alta mar" y en el continente antártico ${ }^{8}$ constituye aún tema de ardua discusión y debate.

- Ia disposición $\rightarrow$ o falta de ella- de recursos científicos y tecnológicos adecuados modifica drásticamente las alternativas accesibles a los miembros del Tratado para la investigación y explota-

${ }^{8} \mathrm{Al}$ respecto, ver distintas posiciones. Entre ellas: Auburn, "Offshore Oil and Gas", pp. 154-155; Hearings, 1975, pp. 19-20): Sollie, 1979, p. 207. El Art. vi del Tratado establece que "las disposiciones del presente Tratado se aplicarán a la región situada al sur de los $60^{\circ}$ de latitud sur, incluidas todas las barreras de hielo; pero nada en el presente Tratado perjudicará o afectará en modo alguno los derechos o el ejercicio de los derechos de cualquier Estado conforme al Derecho Internacional en lo relativo al altamar dentro de esa región". 
ción de los recursos. Pero también resulta de enorme relevancia para aquellos actores nacionales y transnacionales que tienen interés en incorporarse activamente a la futura explotación de los mismos, preferentemente bajo Ios términos del Tratado pero no inelu. diblemente bajo éstos. La innovación en ciencia y tecnología contribuye asimismo a modificar la importancia asignada a uno $u$ otro recurso en función de viabilidad de su explotación y uso. Es necesario entonces examinar cuál es la situación de los actores en cuanto a su acceso al uso de ciencia y tecnología. De igual manera deben explorarse los posibles cambios que la innovación científica y los usos mundiales de los recursos naturales pueden traer aparejados, no sólo en cuanto a los de viabilidad de su explotación sino también con respecto a su importancia económica relativa.

- La modificación de los criterios geopolíticos y estratégicos tradicionales resulta en función de la complejidad e interacción multisectorial que presenta, con tendencias de rápido crecimiento, el sistema mundial en su conjunto.

Los factores citados pueden ser organizados para su tratamiento según distintos criterios. En este caso han sido agrupados en el marco general que ofrece el "estado de transición" del régimen internacional, prestándose particular atención a los factores estratégicos, económicos y de seguridad y al impacto del avance de la ciencia y la tecnología en estos campos. Esta división no debe hacer perder de vista la interacción existente entre ellos y su interdependencia.

\section{EL "Estado de TRANSICIÓN" DEL RÉGIMEN INTERNaGional}

\section{La Antártida frente al NDM}

Si bien aún resulta prematuro vaticinar los resultados finales que se obtendrán durante las próximas sesiones de la Conferencia de Ia oNU sobre el Derecho del Mar, es dable identificar sus problemas esenciales. La mayor parte se halla centrada en los intereses contrapuestos con respecto a delimitacion, usos y jurisdicción por parte de las diversas categorías de actores: países en desarrollo y naciones industrializadas, las naciones con y sin litoral marítimo; las grandes potencias marítimas tradicionales y los países medianos y pequeños con armadas costeras.

Discutir el futuro de la minería oceánica, pesca, navegación, comunicaciones e investigación científica significa abordar un conjunto de temas claves para el Nuevo Orden Internacional. A través de ellos surgen los conflictos sobre materias primas, energía, alimentos, comercio internacional, política científica y condiciones de seguridad, control y reducción de armamentos, medio ambiente, 
participación de actores transnacionales y, en general, el amplio campo del desarrollo económico'. En parte estos temas han encontrado ya alguna forma de acuerdo en el elaborado Texto Integrado Oficioso para Fines de Negociación (TrofN), que constituye el documento vertebral de la Conferencia. No obstante su difícil tratamiento, dejará pendientes muchos puntos susceptibles de generar tensiones en el futuro, aun cuando se llegue a un acuerdo final exitoso.

Estos problemas surgen de un cambio fundamental en la concepción y el uso del espacio oceánico10 auspiciada por los países en desarrollo en búsqueda de una redistribución de los recursos y el poder a escala mundial.

En efecto. Se pasa de una actitud tradicional, basada fundamentalmente en usos (Ej.: pesca y transporte) (con sus correspondientes dimensiones militares) a una visión política que incorpora conceptos espaciales terrestres. $\mathrm{El}$ mar sin fronteras se transforma en un mar territorial. Desde el punto de vista jurídico se pasa de un derecho de uso a un derecho de apropiación ${ }^{11}$.

La territorialización del océano con un sentido nacional se percibe claramente en la significativa expansión del espacio que podrá controlar y explotar el Estado-Nación, bajo diferentes regímenes. Estos cambios, liderados por el Tercer Mundo, incluyen entre otros una nueva y vasta zona económica exclusiva, derechos especiales para los Estados ubicados en situación geográfica clesventajosa, archipiélagos y sin litoral; el régimen legal de la plataforma continental y las posibilidades que brindará el aprovechamiento compartido de los fondos marinos y oceánicos situados fuera de la jurisdicción nacional bajo el régimen de "Patrimonio Común de la Humanidad"12.

Estos cambios fundamentales en los objetivos político-económicos (el sentido de la apropiación), junto a nuevos y más intensos usos de Ios recursos oceánicos posibilitados por la tecnologia, constituyen el terreno conflictivo de vinculación entre el NDM y el régimen del TA. En sintesis, se tratará de la aparición de conflictos

\footnotetext{
'Pardo, Arvid, "The Evolving Law of the Sea: A Critique of the Informal Composite Negotiating Tex" (1977), in Ocean Yearbook 1, (Chicago, UsA, Univ. of Chicago Press, 1978), pp. 10-11.

10El término "espacio oceánico" es utilizado aquí para indicar la superficie del mar, la columna del agua, el lecho y el subsuelo oceánico.

"Dupuy, J. "The New Law of the Sea", Regional Course of Refereshment in International Law, UNITAR - The Hague Academy of International Law, GEsstw, México, mayo de 1979.

13Por Resolución No 2749, xxv, la Asamblea General de la oNu declaró en diciembre de 1970 que "los fondos marinos y oceánicos y su subsuelo fuera de los límites de la jurisdicción nacional, así como los recursos de la zona, son patrimonio común de la Humanidad". El mismo texto se halla incluido en el TIOFN.
} 
de jurisdicción y soberanía entre el NDir y el Tratado. Actualmente sus principales aspectos estarán referidos al estatus jurídico de la Antártida y el aprovechamiento de sus recursos en la plataforma continental y en las aguas oceánicas que la circundạn.

\section{El estatus juridico de la Antártida}

Existen encontradas interpretaciones sobre el estatus de la Antártida, que apoyan los distintos intereses en juego. Los países del TA con reclamos territoriales han sostenido que este continente, como cualquier otra región del mundo, puede ser objeto del ejercicio de la soberanía nacional. Otras naciones -entre ellas la URss y los eE. uu.- consideran que la Antártida es "Terra Nullius": que no admite adquisición territorial en razón de que su ambiente hostil impide satisfacer los requisitos establecidos por el derecho internacional tradicional (Ej.: "ocupación permanente del espacio"; Hannesian, 1974, p. 67).

Por último, surge ahora con mayor fuerza tras la aceptación internacional del concepto de "Patrimonio Común de la Humanidad" en el caso del NDMr, la noción de que la Antártida es "Res Communis"; que el continente debe pertenecer a la comunidad internacional en su conjunto y sus riquezas distribuidas con justicia entre todos los estados, dando lugar preferente a aquellos de menor desarrollo.

Resulta obvio que la atención puesta sobre el futuro de la Antártida se halla indisolublemente ligada en este momento a sus potenciales riquezas de petróleo y' gas y a las ya muy concretas de pesca de krill y otras especies. Las distintas posiciones jurídicas deben ser por lo tanto sometidas a una lectura política, ya que en gran medida expresan racionalizaciones (propuestas para el establecimiento de reglas de distribución y uso de valores privilegiados) de los intereses políticos, económicos y estratégicos que se persiguen.

En efecto. Sin intentar una discusión de las distintas interpretaciones ${ }^{13}$, lo que se desea destacar es que el subsuelo de la flora jurídica está compuesto por un manto de "realpolitik". Los países con reclamos territoriales arguyen coherentemente que no puede aplicarse para rechazar sus fundamentadas adquisiciones un de-

${ }^{2}$ Distintos juicios sobre el particular surgen, entre otros especialistas, de: Guyer, 1978, pp. 157-164; Auburn, 1977, pp. 156-56: Hearings, us. 1975; "Legal Status of Areas South of 609 S latitude", pp, 18-20; The Fridtjof Nansen Foundation Meeting on Mineral Exploiration..., 1973; Wilson, G. "Antartica, the Southern Ocean and the Law of the Sea, JAG, Vol. 30, No 1, 1978; Bernhardt, J. "Sovereignity in Antartica", cwILJ, (Calif. Western Internat. Law Journal), Vol. 5; 1974-75; Hannessian, National Interests in Antartica, New Zealand Antartic Society, 1965. 
recho que no se adapta a las circunstancias especiales que ofrece la Antártida, en un período donde la creatividad y la adaptación del derecho a los gigantescos avances en todos los campos se halla a la orden del día (el NDM es justamente un ejemplo de ello). Además, varios de estos estados presentan avanzados rasgos de "ocupación permanente"14 del territorio.

El no reconocimiento de los reclamos ubica a los EE. UU. y la uRss en una excelente posición relativa. Principios tales como garantizar "el libre acceso al desarrollo de los recursos naturales" y el "establecimiento de reglas no preferenciales y uniformes" que permitan a todos los miembros del TA acceder a los recursos en cualquier zona de la Antártida, forman parte de la política oficial norteamerican ${ }^{15}$, pero también resultan convenientes a los soviéticos. De esta forma, mientras se mantienen la igualdad formal de las posibilidades de exploración y explotación de los recursos, en la práctica resultarán totalmente asimétricas (Ver Cuadros 5, 6, 7, 8), en virtud de las enormes diferencias en la capacidad financiera, científica y tecnológica de los miembros desarrollados del Tratado con respecto a las naciones en desarrollo.

A éstas - con excepción de aquellas que son miembros consultivos del TA- les resulta conveniente adherir a la posición de "Res Communis", ya que maximiza su posibilidad de participar en los beneficios que acarree Ia explotación de recursos que de otra manera se hallarían fuera de su alcance, en virtud de una insuficiencia tecnológica y económica que no les permite alcanzar la categoría de adherentes.

Esta referencia a las realidades políticas sugiere que la evolución del derecho internacional y su legitimidad no resulta sólo del producto de una aceptación consensual de valores privilegiados, sino también la expresión de relaciones de poder y de funciones sociales, políticas y económicas que varían dinámicamente.

${ }^{14}$ Los fundamentos de las posiciones adoptadas por los países latinoamericanos con estatus consultivo (Argentina y Chile) y adherentes (Brasil) pueden ser precisadas a través de -entre otros- los trabajos de J. G. Puig, La Antártida Argentina ante el Derecho, Depalma, Bs. Aires, 1960; O. Pinochet de la Barra, La Antártida Chilena. Edit. Andrés Bello, $4^{\text {a }}$ edición, Santiago, 1976; T. de Castro, Rumo A Antártica, Freitas Bastos, Río de Janeiro, 1976. (Brasil no ha hecho hasta el momento ninguna reclamación oficial de territorio antártico).

Las ocupaciones de territorio y el ejercicio de la soberanfa que más se adaptan al Derecho Internacional tradicional (en cuanto a su extensión. en el tiempo y las actividades realizadas) se registran en los sectores comprendidos por los reclamos -en disputa- de tres paises: Argentina, Chile y Gran Bretaña. En particular, Argentina posee ya población civil y colegios, habiéndose registrado nacimientos de hijos de ciudadanos argentinos en el sector reclamado por ese país.

IVVer Hearings, us, 1975, Declaraciones de Dixy Lee Ray, Secretario Asistente de Estado, p. 5. 
Carlos $/$. Moneta $/$ América Latina y el sistema internacional en la década...

\section{Cuadro 5}

PAISES SEDE DE MATRICES DE EMPRESAS TRANSNACIONALES Y NACIONALES QUE REALIZAN INVESTIGACIONES EN MATERIA DE NODULOS MINERALES

$\begin{array}{ll}\text { Francia } & \text { URss } \\ \text { Japón } & \text { Rep. Federal Alemana } \\ \text { EE. UU. } & \text { Inglaterra } \\ & \text { Bélgica. }\end{array}$

Fuente: Docto. onu, A/AG 138/36, may 1971; UNGTAD, 1974; TD/B/484-3; Moneta, C., "Intereses Argentinos en el Atlántico Sur: el caso de las riquezas mineras en alta mar", en Millia, edit., La Atlantártida. Un espacio geopolitico, obr. cit.

Cuadro 6

PAISES SON CAPACIDAD DE INVESTIGAGION Y DESARROLLO EN HIDROGARBUROS (OFFSHORE) PARA LAS CONDIGIONES ANTARTICAS

(Empresas estatales, privadas o transnacionales con matriz de ese pais)

$\begin{array}{ll}\text { EE. UU. } & \text { Gran Bretaña } \\ \text { URSS } & \text { Rep. Federal Alemana } \\ \text { Japón } & \text { Bélgica } \\ \text { Noruega } & \end{array}$

FUENTE: OFFSHORE, june 20, 1979; june 20, 1978; WORLD OCEAN, 1978-79.

Cuadro 7

PAISES GON GAPACIDAD FINANGIERA PARA REALIZAR EXPLORAGION Y EXPLOTAGION DE HIDROCARBUROS Y MINERALES EN

LA ANTARTIDA, EN FORMA AUTONOMA

$\begin{array}{ll}\text { EE. UU. } & \text { Rep. Federal Alemana } \\ \text { Gran Bretaña } & \text { Japón } \\ \text { URSS } & \text { Rep. Democrática Alemana* }\end{array}$

* Probable.

La determinación de la capacidad financiera tuvo en cuenta indicadores económicos y financieros generales y las inversiones previamente realizadas en materia de prospección y explotación oceánica de hidrocarburos, en función de costos estimados de exploración y explotación en la Antártida. 
Guadro 8

PAISES MIEMBROS DEL TA (O QUE SE ESTIMA QUE PARTICIPARAN EN EL PROXIMAMENTE), QUE REQUIEREN COLABORACION FINANCIRA Y/O TEGNOLOGICA PARA REALIZAR EXPLORACION Y EXPLOTAGION DE HIDROCARBUROS Y MINERALES EN LA ANTARTIDA*

\begin{tabular}{lll}
\hline Argentina & Chile & Rep. Sudafricana \\
Brasil & Australia & Uruguay \\
Checoslovaquia & Dinamarca & Rumania \\
Nueva Zelandia & Rep. Democ. Alemana & Bélgica \\
\hline
\end{tabular}

* Se utiliźó el mismo criterio que en el Cuadro No 7.

Deben entonces ser tenidos en cuenta -en difícil armonía- los valores e intereses de la comunidad internacional junto a aquellos de Ios países miembros del Tratado. Los problemas concretos surgen en distintos planos: a) el grado de aceptación del TA por la comunidad internacional; b) las indefiniciones internas del 'Tratadocon respecto a la exploración y explotación de los recursos y los límites geográficos que pueden ser aplicados a este acuerdo internacional.

Con respecto a la aceptación del Tratado, teniendo en cuenta las conductas y declaraciones a él referidas por parte de los actores del sistema internacional, puede considerarse que hasta el presente ha sido aceptado por el conjunto de estados-naciones. No obstante, ya han surgido expresiones de oposición. Un indicador emana precisamente de la evolución de la Conferencia de la ONU sobre el Derecho del Mar (CONFEMAR) . En ella ha habido declaraciones - tales como la del Presidente de la Conferencia y de otros delegados ${ }^{16}$ - que señalan un creciente interés por parte del Tercer Mundo de promover la aceptación de principios y mecanismos de cooperación económica internacional que le permitan compartir los recursos de la Antártida.

En realidad el ataque realmente no está dirigido contra el Tratado en sí mismo sino en tanto es percibido como un probable instrumento de legitimación para que un reducido grupo de paísẹs monopolice los beneficios. En la medida en que los miembros del $T A$ se hallen dispuestos a encontrar alguna fórmula que permita satisfacer en grado sustantivo esos intereses económicos, las puertas se hallarán evidentemente abiertas para la negociación.

Los del ra se hallan muy conscientes de la nueva situación y parecen dispuestos a buscar modalidades de solución que puedan: sa-

18Por ejemplo existen varias declaraciones del Embajador: Amerasinghe (Sri Lanka), Presidente de la Conferencia, en este sentido. 
tisfacer a las partes. El comunicado emitido por los miembros al finalizar su Décima Reunión Consultiva, afirma simultáneamente sus derechos y la responsabilidad que les cabe de encontrar respuestas satisfactorias dentro del marco del Tratado, que además de resolver los problemas internos permitan que "el tratamiento efectivo de estos temas sea balanceado con la necesidad de que los intereses de toda la Humanidad en la Antártida no se vean perjudicados". En su conjunto, el Documento -como así también las declaraciones individuales de varias de las delegaciones ${ }^{17}$ - constituye una reafirmación de la vigencia del Tratado y de la voluntad de las partes "de mantener el sistema" cuando "nuevos temas relacionados con los recursos antárticos se presentan en primer plano"18.

Resulta evidente que el Tratado, con veinte años de vigencia y un buen nivel de cumplimiento de sus objetivos, forma ya parte del conjunto de documentos internacionalmente reconocidos ${ }^{18}$. Constituye uno de los "casos especiales" a los cuales el derecho en su evolución, ha comenzado a reconocer y a tratar como tales. Escapa, por lo tanto, a los rígidos criterios del derecho internacional tradicional (Guyer, 1973, pp. 153-54). Ello responde no sólo a la lógica sino a un sentido de justicia que impone tanto el reconocimiento de los derechos de sus miembros (Van Essen 1975-76), pp. 95-96), como así también el del resto de la comunidad mundial. Es precisamente esta parte la que debe desarrollarse en esta nueva etapa de la vida del Tratado. El peligro que se cierne sobre el futuro del Tratado parece depender entonces de su capacidad como instrumento apto para la resolución de problemas de propiedad, control, administración y regulación de los recursos naturales entre sus propios miembros, y entre éstos y la comunidad internacional.

\section{LOS CONFLICTOS VINGULADOS A LA EXPLOTACIÓN DE LOS RECURSOS}

Si bien su dimensión y valor comercial es aún objeto de serias discusiones, existen depósitos de cobre, manganeso, uranio, carbón, platino, cromo, berilio, cobalto, níquel, titanio, oro, plata y hierro. Por un largo período no se espera que resulte factible ni económicamente rentable la explotación de la mayor parte de estos minerales.

${ }^{17}$ Press Communique, Washington DG, Oct. 10, 1979 (la traducción de la versión inglesa es del autor).

${ }^{18}$ Por ejemplo: "Antartica: 10th Meeting of Treaty Consultative Parties", UsA, Department of State Bulletin, November 1979.

Iopress Communique, ibid. 
La ubicación de estos depósitos varía, pero la Península Antártica alberga a casi todos los minerales. En cuanto a las concentraciones conocidas más importantes, corresponden al hierro y al carbón. Se hallan localizadas en las montañas del Príncipe Carlos \% en la Cordillera Transantártica, respectivamente ${ }^{20}$.

Existen nódulos minerales, pero hay muchas otras áreas del mundo más prometedoras y accesibles. En cambio, en el océano que rodea a la Antártida la situación es distinta; la plataforma conc.nental parece albergar cantidades de petróleo y gas que oscilan sensiblemente según las fuentes y los expertos consultados ${ }^{21}$, pero que se hallan entre los quince mil millones de barriles de petróleo y cantidades muy superiores a los cincuenta mil millones. Nuevamente, los mares de la Península Antártica, adonde se superponen los reclamos territoriales de Argentina, Chile e Inglaterra resultan de las áreas privilegiadas. Las plataformas del Mar de Wedell (Argentina, Chile y Gran Bretaña) y del Mar de Bellingshausen (Argentina, Chile y Gran Bretaña), junto al Mar de Ross (Nueva Zelandia) y al Mar de Admunsen (Zona no reclamada), son consideradas las áreas más prometedoras ${ }^{22}$.

$\mathrm{El}$ océano también contiene recursos renovables. Entre ellos se destaca plenamente el krill, de alto valor proteínico. Su aprovechamiento se halla aún en su etapa experimental, su pesca es aún muy limitada - menos de las 200.000 toneladas anuales, en su mayor parte extraídas por la uRss, Japón y Polonia- (ver Cuadro 18)

\section{Cuadro 9}

PAISES QUE HAN RECIBIDO SOLICITUDES PARA CONGESION DE LICENCIAS DE EXPLORACION Y EXPLOTACION COMERCIAL DE HIDROCARBUROS EN LA ARTARTIDA*

\begin{tabular}{lll}
\hline EE. Uv. & Gran Bretaña \\
Japón & Australia \\
Nueva Zelandia &
\end{tabular}

*Esta lista es meramente indicativa y ha sido elaborada utilizando fuentes de carácter público. Por lo tanto, es posible que otros paises hayan recibido este tipo de solicitudes.

"Ver "Mineral Resources of Antartica", Geological Circular 705, Hearings, us. 1975 y "Antartic Resources...", The Fridtjof Nansen, op. cit.

"Ver "Mineral Resources in Antartica, op. cit. pp. 53-55; Antartic Resources.... op. cit.; Tinker, $\mathrm{J}$. and Holdgate, M. Oil and Minerals in the Antartic, (The Bellagio Report), SCAR, Scott Polar Research Institute, U.K. 1979; Tinker, J. "Antartic: Towards a New Internationalism "New Scientist"; London, 13 September 1979, pp. 799-801.

*Ver nota No 20. 
y su ciclo biológico no es completamente conocido. La capacidad de pesca anual se estima en el orden de las 100 millones de toneladas, frente a las 70 millones que presenta el conjunto de la pesca mundial total ${ }^{23}$.

Gran parte de las mayores concentraciones de krill se encuentran dentro de las 200 millas de las costas de la Península Antártica y en el Mar de Wedell en aguas cercanas a las islas Orcadas, Sandwich y Georgias, es decir, en los sectores antárticos disputados por Argentina e Inglaterra.

¿A qué régimen será sometida la explotación de todas estas riquezas? El TA no contiene en sus artículos referencias específicas a la exploración y explotación de los recursos ${ }^{24}$, excepto en cuanto las hace a la protección y conservación de los recursos vivos (Art. 9, f). Sin embargo, el Tratado contiene otras previsiones ${ }^{25}$, que otorgan fundamentos jurídicos a los estados miembros a través de nuevos esfuerzos - derivados del marco del Tratado- para actuar en esta materia. En virtud de ello se ha elaborado una Convención para la conservación de los recursos marinos renovables quc aún no ha sido aprobada. Esta Gonvención extiende su jurisdicción hasta la "convergencia Antártica". También se están anali. zando, desde los primeros años de la década del $70^{26}$, las bases y el contenido de una futura convención sobre los recursos minerales e hidrocarburos.

En cuanto a los recursos oceánicos, objeto de la atención inmediata, el problema de la soberanía aparece ligado al régımen a convenir. El Tratado, al establecer sus límites en el paralelo o0ب de latitud sur especilica que ello "no afecta en modo alguno los derechos o el ejercicio de los derechos de cualquier estaclo contorme al "Derecho Internacional en lo relativo a alta mar dentro de esa región" (Art. vr). Dados los avances del NDM en cuanto al régimen de las plataformas continentales y zonas económicas excıusivas (ZEE), cabe preguntarse cuál será la superficie considerada "alta mar", dado que hay estados con reclamos territoriales (que conllevan el derecho a la $\mathrm{zEE}^{27}$ y otros miembros que los desconocen.

Ner: Kimball, L. "Exploración y explotación del kxill: el presente y las perspectivas futuras", en Geopolitica y Politica de Poder en el Atlántico Sur, C. Moneta, compilador, Editorial Pleamar, Bs. Aires, 1980 (en imprenta).

${ }^{n *}$ Ver: Antartic Resources, op. cit. pp. L-I.

${ }^{25}$ Ibid, pp. L-I; L-2.

${ }^{20}$ La primera consideración sistemática del tema se realizó en una reunión no oficial de expertos celebrada en Noruega en 1973 (las conclusiones integran el documento "Antartic Resources Report..." ya citado). En la Ix Re unión Consultiva del TA (Londres, 1977), se consideró la organización de un sistema regulado para la exploración y explotación de los recursos, sin a.er tar al medio ambiente.

${ }^{2 \pi}$ Ter: Antartic Resources... op. cit. Ello constituye hoy un principio de derecho universalmente aceptado. 
Guadro 10

PAISES QUE REALIZAN EXPLORACION OFFSHORE E INVESTIGACION CIENTIFICA SUSCEPTIBLE DE SER APLICADA A FINES COMERGIALES, EN LA ANTARTIDA

\begin{tabular}{lll}
\hline EE. uU. & Australia & Rep. Dem. Alemana \\
Gran Bretaña & Japón* & Polonia* \\
Nueva Zelandia* & Noruega & Rep. Sudafricana* \\
Argentina & Erancia & \\
Chile & URss & \\
\hline
\end{tabular}

*Probable.

¿Aceptarán los actores no miembros del Tratado una jurisdicción hasta los $60^{\circ}$ de latitud sur? ¿Hasta la convergencia antártica? ¿O como han propuesto varios especialistas ${ }^{28}$ se reconocerá una especie đe "Zona Económica Exclusiva" que rodee a todo el Continente y a las islas comprendidas dentro de los $60^{\circ}$ de latitud sur?

En cuanto a los recursos vivos, la Convención, mediante un artificio jurídico, pretende, sin que se pueda vaticinar el resultado, satisfacer simultáneamente los nuevos requerimientos del derecho del mar (las $\mathrm{zEE}$ ) y la posición de aquellos estados que no reconociendo reclamos, desean asegurarse el libre acceso a las 200 millas a lo largo de la costa antártica. Resulta cuando menos dudoso que idéntico mecanismo pueda ser aplicado con exito para la explotación del petróleo y gas en la plataforma continental.

Faltaría aún considerar recursos de futura explotación, como los témpanos (la Antártida encierra el 90\% del agua dulce del mundo) en la explotación de los cuales ya han demostrado interés algunos países árabes ${ }^{29}$.

Innumerables fuentes de posibles conflictos de jurisdicción surgen de estos nuevos regímenes en formación. Por ejemplo, la obligatoriedad de los mismos para terceros estados; la coordinación de actividades y delimitación de áreas entre jurisdicción nacional; jurisdicción del TA y jurisdicción del NDM, constituyendo el caso típico la futura relación a establecerse entre los miembros del TA y

sver, entre otros, Van Essen, 1975, pp. 95-96; Sollie, 1979, p. 207. Para una apreciación distinta de estas posibilidades, ver Wilson, G. "Antartica, The Southern Ocean, and...", op. cit.

${ }^{20}$ Entre la bibliografia juridica existente sobre el tema, ver el artículo de Hannessian, "Overview: Some International...", en Science, Technology.. op. cit. Ver: "Bringing home the iceberg", by John Ludwingson, in Ocean World, N. York, USA, January 1978, pp. 29-33; Newsweek, N. Y., July 4, 1977, p. 72; Wall Street Journal, N. Y., October 5,1977 , p. 1 . 
Guadro 11

INDICADORES DE GAPACIDAD MARITIMA GENERAL DE PAISES DE LA SUBREGION AUSTRAL DEL HEMISFERTO SUR: FLOTAS MERGANTES

(al $1^{\circ}$ de julio de 1977)

\begin{tabular}{lr}
\hline \multicolumn{1}{c}{ Pais } & Tonelaje \\
\hline Argentina & 1.676 .169 \\
Brasil & $3.329: 951$ \\
Chile & 409.971 \\
Uruguay & 192.792 \\
Rep. Sudafricana & 476.324 \\
Australia & 1.374 .197 \\
(A fines comparativos): & 15.299 .681 \\
EE. uu. & 21.438 .291 \\
URss & \\
\hline
\end{tabular}

FunNTE: Lloyd's Register of Shipping: Statistical Tables.

la Autoridad creada por el NDM para la administración de los recursos situados más allá de las jurisdicciones nacionales.

La simple enumeración de algunas de las vinculaciones cooperativas y conflictivas más probables entre los distintos actores -varias de las cuales ya se han presentado en los hechos- da una idea de la magnitud de los problemas a enfrentar:

- En el marco del Tratado Antártico

- Estados reclamantes Vs. No reclamantes.

- Estados reclamantes entre si (Ej.: Argentina, Chile, Gran Bretaña).

- Estados no reclamantes entre sí (Ej.: EE. UU., URss).

- Estados no pesquerios vs. pesqueros (Ej.: Japón, URss, Polonia, Alemania Oriental).

- Estados conservacionistas (no desean encarar todavía la explotación de por lo menos algunos de los recursos) $\mathrm{v} / \mathrm{s}$ Estados que promueven una pronta explotación de los mismos (Ej.: URssEE. UU) .

- Estados con recursos científico-tecnológico y financieros significativos $\mathrm{v} / \mathrm{s}$ Estados que los poseen en grado suficiente (Países desarrollados $\mathrm{v} / \mathrm{s}$ Paises en desarrollo) .

- Estados con status de Parte Consultiva v/s Estados Adherentes (Ej.: Argentina y/o Chile v/s Brasil).

-En el contexto "sistema global-subsistema antártico"

- Estados miembros del TA V/s Estados no miembros (divisible a 
su vez en: Estados con estatus consultivo $\mathrm{v} / \mathrm{s}$ Estados no miembros, Estados adherentes $\mathrm{v} / \mathrm{s}$ Estados no miembros, etc.)

- Estados miembros $\mathrm{v} / \mathrm{s}$ actores transnacionales (Ej.: ETN, Asociaciones No Gubernamentales).

- Estados miembros $\mathrm{v} / \mathrm{s}$ Organismos Internacionales (Ej.: FAO, UNEP) .

- Estados miembros $\mathrm{v} / \mathrm{s}$ actores subnacionales (Ej.: grupos de protección ecológica, etc.).

Esta simple presentación se enriquece en la práctica con un variado espectro de combinaciones ( $\mathrm{Ej}$.: Estados no miembros sin recursos y Estados no miembros con recursos $\dot{v} / s$ Estados miembros con recursos). Asimismo, a esta lista debe agregarse las polarizaciones que surgen de los factores de seguridad. El resultado muy probable es el de un subsistema de creciente complejidad que desarrollará viticulaciones funcionales-sectoriales de carácter cooperativo-conflictivo entre los distintos actores del sistema global a nivel subnacional, nacional $y$ transnacional. Las polarizaciones $y$ alianzas que surgen en el marco de las convencionales coordenadas Norte-Sur y Este-Oeste se modifican sensiblemente en virtud de estos nuevos factores.

La capacidad de percibir claramente Ios cambios estructurales, el impacto de las nuevas fuerzas políticas y económicas que actúan, las contradicciones que se generan y las consiguientes aperturas que se presentan para la formulación de estrategias más heterodoxas, serán entonces uno de los elementos esenciales para incrementar efectivamente la capacidad de negociación de los países en desarrollo, formen o no parte del TA."

\section{El SUBSISTEMA ANTÁRTICO FRENTE A LOS PROBLEMAS DE SEGURIDAD ESTRATÉGICA}

Las últimas décadas han introducido cambios importantes en las percepciones y capacidades estratégicas de los actores con intereses marítimos. Para las potencias tradicionales, estos años han generado creciente incertidumbre ante los signos de declinación de su supremacía naval, dada la aparición de una nueva potencia marítima de posibilidades globales (la unss) y de varios actores emergentes del Tercer Mundo con capacidades regionales ${ }^{\mathbf{3 0}}$.

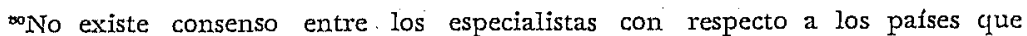
deben ser incluidos en esa categoria. Entre ellos figuran Brasil, Chile, Argentina, India, España y Japón. (Ver: Wemyss, A. F. C. "The part played by naval forces in the international scene". The South African Institute of International Affairs, Vol. 5, No 4, Johannesburg, December 1974, p. 26. También Daly Hayes, "Bràsil y el Atlántico Sur: cambio de perspectiva sobre un tema importante", en Geopolitica y Politica de Poder en el Atlántico. Sur, op. 
PAISES QUE YA HAN REALIZADO O ESTAN POR REALIZAR AFIRMACIONES DE SOBERANIA SOBRE LAS 200 MILLAS DE.ZEE EN LA ANTARTIDA

\begin{tabular}{ll}
\hline & \\
Argentina & Australia \\
Chile & Francia (Islas Kerguelen) \\
& Nueva Zelandia \\
\hline
\end{tabular}

\author{
Cuadro 13 \\ PETROLEO Y GAS: VINCULACIONES DE ARGENTINA Y CHILE \\ CON EMPRESAS EXTRANJERAS* \\ (Subcontratación; concesiones; etc.)
}

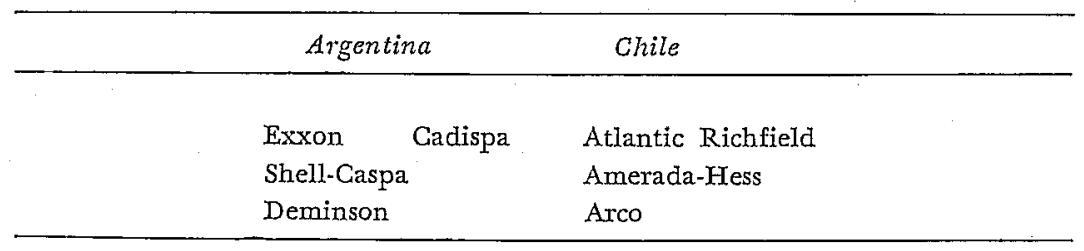

FUENTE: OFFSHORE, june 20, 1978; wORLD OIL, july 1979; OFFshore, february. 1979.

* Esta lista no pretende ser exhaustiva con respecto a la actividad offshore que se realiza frente a las costas de ambos paises. Solamente registra los principales acuerdos.

Estos nuevos acontecimientos afectaron su capacidad de control de las actividades oceánicas en tiempo de paz (es decir, en este período de conflictos locales, de carácter limitado). No obstante, su capacidad financiera y de innovación tečnológica les permite mantener cierto predominio en el área militar y en el campo de las actividades económicas (en este plano, en conjunción'con las ETN).

La ideología tacionalizadora" de la supremacía naval -la "libertad de los mares"- tuvo que dar paso -ahora bajo ideologías reivindicativas- a la territorialización e internacionalización del espacio oceánico. El statu quo, que fue quebrado, pero en el terreno militar y los objetivos de mantenimiento del control estratégico naval y de uso de los recursos oceánicos permanecen, si biẹ déeben adàptarse a las nuevas condiciones existentes. En consecuen-

cit.; Morris, M. "Have Us, security interests 'really been sacrificed? A reply.., to Admiral Hill", Ocean Development and International Law, Vol. 4, 1977; Crane Russak, N. Y.; Moneta Carlos, "Aspectos conflictivos de las relaciones afro-latinoamericanas...", art. cit., en Geopolitica y Politica de Poder..., obr. cit. 
cia, la estrategia y diplomacia naval van a ser afectadas por los cambios económicos, polfticos y tecnológicos (Booth, 1979, págs. 329-330).

El NDM fue percibido por los especialistas norteamericanos y británicos ${ }^{31}$, como un serio obstáculo para la utilización del poder naval, dado que significa restricciones al uso de las cuatro dimensiones del espacio oceánico -el lecho, el subsuelo, la superficie y el espacio aéreo- necesarias para la satisfacción de los objetivos de seguridad. Estos últimos consisten en: a) el mantenimiento de una capacidad estratégica nuclear frente a la uRss (a través de la posibilidad de sobrevuelo de aeronaves militares y del pasaje no anunciado de fuerzas submarinas nucleares de inmersión por estrechos y zonas ubicadas más allá de las doce millas); b) el mantenimiento de la capacidad de maniobra y de envío de fuerzas navales norteamericanas a zonas distantes, para el caso de guerra limitadas y localizadas; c) las operaciones de inteligencia militar (Ei.: por intermedio de la ubicación de artefactos de detección de actividades submarinas en la plataforma continental); d) la protección de la población, los intereses comerciales y el acceso a recursos $\operatorname{crfticos}^{32}$.

La marina de la Unión Soviética coincide con la de los EE. UU, en su misión de disuasión estratégica nuclear, al igual que en la realización de operaciones de inteligencia militar y maniobra naval. En cuanto a la proyección de las fuerzas soviéticas en caso de conflictos en zonas muy alejadas de su territorio, la URSS indudablemente se está preparando activamente para ello ${ }^{33}$. En la etapa actual, sin embargo, es muy importante incrementar su capacidad de "mostrar el pabellón" en teatros distantes en el Tercer Mundo, ejercer a través de ello una acción disuasiva y desarrollar su capacidad de "negar el acceso" a las líneas de comunicación occidental (Morris, E., 1976, pp. 66-67; Mangone, 1978, p. 72; Gorshkov).

Dada la creciente globalización de la estrategia naval soviética, resulta factible esperar que se incremente en cierto grado su presencia en el Indico y el Atlántico Sur, dado que sus intereses en la zona comienzan a superar el simple nivel subregional.

s1Ver, entre otros: Osgood, 1974; Booth, 1979; Mangone, 1978; Hollick, 1974; Morris E., 1976; Knikht, 1974; Buzan, 1976; Real Admiral Hill, c.u.s. Navy (Ret.) "Us Law of the Sea Position and its effects on the operating Navy: A Navals Officer View", Ocean Development an International Law, Vol. 3, Pp. 341-359, 1976.

32Ver Osgood, 1974, pp. 78-79; Knight, 1974, pp. 22-24; Congress and the Oceans: Marine Affairs in the 94th Congress, Committee on Commerce, Science v.s. Government Printing Office, Washington, D. C., 1977. (A partir de ahora, denominado Congress and the Oceans, us, 1977).

Ver cifras sobre construcción y tipo de unidades soviéticas en la publicación Jane's Fighting Ships, (London). Ver asimismo: "Russian Navy: a New Interest in the Third World", NY Times, 10 Dic. 1979. 
Cuadro 14

PACTOS DE CARACTER MILITAR A QUE PERTENECEN LOS PAISES

DEL TRATADO ANTARTICO

a) Tratado Interamericano de Defensa (TIAR)

Argentina, Brasil, Chile, EE. uU.

b) NATO.

EE. UU., Francia, Inglaterra, Holanda, Rep. Fed. Alemana.

c) Pacto de Varsovia.

URss, Polonia, Rumania, Rep. Democrática Alemana.

'd) Acuerdos bilaterales $y$ otros (ejemplos).

Japón-eE. uU.; Rep. Federal Alemana-Gran Bretaña-EE. UU..Francia-URss.

Estos intereses de seguridad determinaron que la política de las grandes potencias buscara en las negociaciones de la CONFEMAR: a) asegurar su capacidad de acceso a aguas lejanas mediante el mantenimiento del derecho de libre pasaje; b) que la ZEE no significara un poder de control y jurisdicción por parte del estado costero muy superior al ya existente; c) el derecho de sobrevuelo para aeronaves militares sobre estrechos internacionales; d) la libertad de investigación científica y e) la posibilidad de emplazar equipos de detección en la plataforma continental.

En términos estratégicos el escenario básico consiste en el mantenimiento de la competencia global con la uRss por un período indefinido "durante el cual la competición entre las superpotencias va a ser afectada por continuos disturbios en la periferia del mundo desarrollado" (Osggod, 1974, p. 114). Es decir, se espera un incremento de las tensiones y conflictos en las regiones en desarrollo.

Para las potencias navales de alcance regional o subregional, el NDM en vez de ser un obstáculo constituye una suerte de paraguas legal bajo el cual aumenta su capacidad de negociación y control vis a vis las grandes potencias. Los nuevos territorios oceánicos traen aparejados un mayor requerimiento de vigilancia y, en consecuencia, la necesidad de contar con fuerzas navales más numerosas y modernas. La innovación tecnológica, al introducir cohetes en la guerra naval susceptibles de ser montados en embarcaciones intermedias y pequeñas, ofrece cierta capacidad de respuesta táctica disuasiva y las armadas de los países medianos en el caso de conflictos con grandes potencias que se desarrollen en teatros de operaciones locales.

Es posible observar una mutua capacidad de influencia -lamentablemente, asimétrica- entre los factores de seguridad y el nuevo 
Guadro Is

RECONOCIMENTOS MUTUOS DE LOS RECLAMOS TERRITORIALES EN LA ANTARTICA

\author{
Argentina y Chile (entre sí) \\ Australia, Francia, Nueva Zelandia, Noruega e Inglaterra (entre sf)
}

régimen oceánico. Si bien el NDM es capaz de aceptar las operaciones que responden al orden estratégico, en general este último aún mantine su predominio. Al respecto debe señalarse que el NDM admite (por omisión) ciertos privilegios para los intereses militares (Booth, 1979, p. 341). Así, las armadas pueden realizar ejercicios militares en la $\mathrm{ZEE}$ de otros estados; construir plataformas de uso militar y ubicar armamento no nuclear, además de evitar el someter disputas relacionadas con actividades militares a los mecanismos de solución de conflictos previstos por el NDM. Ello condiciona notablemente la capacidad efectiva del NDM de preservar los océanos para usos pacíficos.

En cuanto a las potencias medianas y menores, dado que no les afecta en primer grado la disuasión estratégica nuclear (salvo, claro está, en caso de su quiebra), hallan relativamente más accesible el enfrentamiento directo y localizado con actores de su nivel.

En consecuencia, varias son las consideraciones que resultan de interés para los aspectos de seguridad del subsistema antártico y de sus zonas de influencia:

- EI NDMr y los factores de seguridad estratégica se afectan mutuamente, pero estos últimos prodominan en caso de conflicto. En tiempo de "paz" los estados -muy particularmente las potencias navales tradicionales- continuarán realizando actividades de "presencia naval" en el teatro de operaciones deseado.

- No obstante, el nuevo régimen jurídico y los avances tecnológicos ofrecen mayores oportunidades para una acción independiente en defensa de sus intereses por parte de los países en desarrollo.

- Los problemas a los cuales no ha dado solución el NDE -al igual que los múltiples aspectos de fricción a los cuales dará lugar la aplicación del NDM en el caso de que sea finalmente aprobado-, ofrece amplio campo de acción para el ejercicio de la diplomacia naval basada en el poder militar.

- El Atlántico Sur y su zona de influencia. (Península Antártica; Tierra Reina Mau; Mares de Bellinghausen: y de. Wedell) cobran gradualmente mayor importancia desde el punto de vista de la seguridad, en virtud del desplazamiento de las líneas de 
confrontación estratégica Este-Oeste en Africa al sur de Sahara; la presencia de fuerzas navales de ambas superpotencias en el Indico; la relevancia de los pasajes de comunicación PacíficoAtlántico (América Latina-Antártida) y Atlántico-Indico (Antártida-Africa) y los conflictos de carácter bilateral o subregional que presentan -con distinto grado de importancia- los conos sur de América Latina y Africa.

\section{LOS CAMBIOS DE EENFASTS REGTSTRADOS EN LA CONCEPGIÓN ESTRATÉGICA DE LA ANTÁRTIDA: LA PREEMINENCIA DE LOS INTERESES EGONÓMIICOS}

Durante la Segunda Guerra Mundial, la Antártida adquirió cierto valor militar, ya que los observatorios ingleses allí instalados proveían valiosa información meteorológica. Además, en las aguas que se extienden hacia el norte de la Península Antártica encontraron adecuado punto de acecho los submarinos alemanes que entorpecian el transporte marítimo de alimentos hacia Europa que se iniciaba en la costa atlántica latinoamericana.

La marginalidad geográfica de la Antártida, la ausencia de población y de recursos conocidos, restó relativa importancia estratégica al continente y a las aguas que lo rodean durante varios años, facilitando el acuerdo de no-militarización. No obstante, (o al menos parte de su territorio), la Antártida mantuvo cierto valor mínimo como potencial base de ataque con cohetes a los países australes de América Latina y Africa, al igual que a Nueva Zelandia y Australia. Por otra parte, la.Península Antártica facilita cualquier intento de control de los pasajes oceánicos Pacífico-Atlántico-Indico por parte de actores que posean los necesarios recursos militares, tecnológicos y logísticos.

Como se ha señalado anteriormente, la firma del TA logró uno de sus objetivos -apartar a la Antártida del esquema de la guerra fría- al prohibir su militarización (Art. I). Con ello se evitó la introducción de fuerzas nucleares $y$ aún convencionales, si bien estas últimas actúan regularmente en carácter de proveedores de servicios logíticos y en el cumplimiento de actividades científicas (Art. 1, Inc. 2). No obstante, el peligro de acciones bélicas aisladas o de una militarización futura -ya sea de carácter parcial o temporal- no es descartable en función de varios factores:

- Un retorno a la política de la "guerra fría" en virtud de la evoIución del equilibrio estratégico ̇̇e.UU.-URSs a nivel global, sectorial o regional (Ej.: Golfo Pérsico, Indico, Africa).

- La quiebra formal o de facto del Tratado Antártico, ante la imposibilidad de llegar a un acuerdo entre sus miembros para la 
exploración y explotación de los recursos naturales o ante presiones de otros factores del sistema internacional.

- El uso del poder militar por parte de países cuyos reclamos territoriales se superponen total o parcialmente, para dirimir dicho conflicto.

- Una acción de penetración en el continente o su espacio oceánico por parte de terceros actores, no miembros del Tratado, que no aceptan sus regulaciones.

Gonviene observar, aunque sea brevemente, algunas de estas posibilidades. Hasta el presente la "neutralización" del continente y sus aguas jurisdiccionales ha satisfecho los requerimientos de seguridad de EE. UU. Y la URSS, pero pueden producirse cambios en la situación de equilibrio estratégico que decidan a una superpotencia de correr el riesgo de cambiar las reglas de juego. Existe un amplio espectro de potenciales desequilibrios geopolítico-estratégi$\cos$ en las relaciones soviético-norteamericanas que repercutirian fuertemente en el seno del Tratado (Ej.: "pérdida" de Africa del Sur o del control del Indico por los EE. UU.).

Por otra parte, aún hoy se presentan factores sobre los cuales es posible especular. ¿Se conoce acaso si submarinos nucleares de alguna o ambas de las superpotencias no realizan viajes para obtener informaciones cientifico-militares en las aguas cubiertas por el Tratado? ¿No pueden ya contar con puntos de apoyo potenciales en las costas del continente? Las operaciones de inspección que realizan los miembros del Tratado pueden resultar aptas para identificar instalaciones o equipos especiales a ese objeto, pero no alcanzarían a detectar actividades como las mencionadas en primer término.

Los restantes escenarios seleccionados se centran en conflictos de soberanía y distribución de los recursos. En el caso de las grandes potencias representa el desplazamiento de sus intereses estratégicos hacia la explotación de los recursos oceánicos ${ }^{34}$. Así, por ejemplo, Ann Hollick establece que: "Entre 1973 y 1974 el conflicto (entre Ios grupos gubernamentales y no gubernamentales que participan en el proceso de decisión de los EE. UU.) entre los intereses estratégicos globales y los económicos costeros se fue transformando subterráneamente en un conflicto entre perspectivas político-estratégicas y aquellas orientadas hacia los recursos económicos"... ..."los compromisos políticos (internos) evolucionaron en forma continuada desde posiciones que favorecían los intereses militares-estratégicos hacia posiciones más convenientes a los intereses económicos y costeros", (Hollick, 1974, pp. 1-2).

\footnotetext{
"Ver: "Deep Seabed Minerals: Resources, Diplomacy, and Strategic Interest" us, 1978, pp. 78-90.
} 
Carlos J. Moneta / América Latina y el sistema internacional en la década...

Guadro 16

APREGIAGION TENTATIVA DE LA POSICION DE LOS MIEMBROS DEL

TA CON RESPECTO A LA EXPLORAGION Y EXPLOTACION

COMERGIAL DE MINERALES E HIDROCARBUROS (OFFSHORE)

Pais Posición

URsS

Argentina

Chile

Polonia

Francia

Japón

Gran Bretaña

Bélgica

Brasil

Alemania Federal

Rep. Democ, Alemana

EE. UU.
Opuesta a la explorac. y explotac. (solicita Moratoria). Opuesta a la explorac. y explotac. (solicita Moratoria). Opuesta a la explorac. y explotac. (solicita Moratoria). Opuesta a la explorac. y explotac.

No claramente estimable, tendiendo a favorecer la expl. y explot.

Opuesto a la explorac. y explotac., basado en criterios ecológicos.

Cambio de posición durante los dos últimos años, favoreciendo ahora el criterio comercialista.

A favor de la explorac. y explotac. de los recursos.

Posición no claramente estimable.

(No forma parte del Comité Consultivo). Intormalmente se conoce que favorece la explorac. y explotac. de los recursos.

(No forma parte del C. Consultivo), Se estima favorable a la exploración y explotación de los recursos.

(No forma parte del C. Consultivo). Aún no estimable. A favor de la explorac. y explotación de los recursos.

Estos cambios en las posiciones adoptadas por las grandes potencias occidentales $y$ en particular por los EE. UU. Y la URSS ${ }^{35}$ en las tratativas de cONFEMAR presentan un paralelo en las negociaciones en el seno del ta (ver Cuadros 16 y 17). La diferencia más importante está dada por la oposición de la uRSS a la exploración y explotación comercial de los recursos no renovables ${ }^{36}$, pero ello parece responder a causas distintas (intereses económicos y políticoestratégicos) de las formalmente aducidas. Estas últimas se basan en la protección del medio ecológico, la falta de urgencia para encarar la explotación ante la existencia de reservas en otras zonas

sPara la URss, ver por ejemplo, Hollick, I974; Yakolev, L. "World Order and International Cooperation", "International Affairs", Moscow, June 1978, p. 34; Yarolavtsev, V., "The World Ocean and International Law", International Affairs, Moscow, February, 1975.

${ }^{3 e} \mathrm{La}$ posición soviética fue claramente planteada en la reunión de expertos realizada en Noruega, en 1973 (ver Antartic Resources..., op. cit), continuándose básicamente a lo largo de esa línea hasta el presente. 
Guadro 17

POSIGION DE LOS MIEMBROS DEL TA GON RESPEGTO

A LA PESCA ANTARTICA

(los datos estadísticos no incluyen el krill)

\begin{tabular}{ll}
\hline Pais & Posición \\
\hline & \\
URss & A favor (Pesca, año 1977: 257.829 Tn). \\
Rep. Democ. Alemana & A favor (Pesca, años 1977-78: $10.305 \mathrm{Tn}$ ). \\
Polonia & A favor (Pesca, años 1977-78: $63.523 \mathrm{Tn}$ ). \\
EE. UU. & Opuesto; favorece pesca en forma restrictiva, según crite- \\
& rios ecológicos. \\
Francia & A favor. \\
Australia & A favor; se prepara para participar en pesca. \\
Argentina & A favor, con criterios restrictivos. Se prepara para par- \\
& ticipar. \\
Chile & A favor. Se prepara para participar. \\
Japón & A favor. \\
\hline
\end{tabular}

Fuente: Datos estadísticos obtenidos de FAO y L. Kimball, "Exploración y explotación...", obr. cit.

del mundo más accesibles y a la necesidad de mantener un legado de recursos naturales para las generaciones venideras ${ }^{37}$.

Determinar con cierto rigor las probabilidades de que se presente uno $\mathrm{u}$ otro escenario de conflicto, así como las múltiples combinaciones viables para los actores en sus relaciones cooperativas y antagónicas escapa a las posibilidades de este trabajo. No obstante, pueden señalarse objetivos generales perseguidos por distintos actores no influirán sobre la evolución del proceso.

\section{LOS INTERESES DE LOS PRINGIPALES AGTORES}

Los objetivos estratégico-económicos de los $\mathrm{EE}$. UU.

En 1970, un memorándum de la Casa Blanca ${ }^{38}$ establece las directivas impartidas por el Presidente Nixon para la política norteamericana en la Antártida. Se reitera en este documento que: 1) los EE. UU. desean mantener vigente el $\mathrm{TA} ; 2)$ que el continente continúe siendo usado con fines pacíficos; 3) promover la investi-

${ }^{37}$ Argumentos presentados por los expertos soviéticos en la reunión informal de expertos realizada en Noruega, en 1973 (ver nota anterior).

${ }^{38}$ Office of the White House Press Secretariat, October 13, 1970, Hearings, us, 1975, p. 30. 
gación científica, enfatizando "Ia predicción y evaluación de los recursos" 39 .

Estos propósitos son confirmados y aún ampliados en los informes al Senado realizados por el Secretario Asistente de Estado (que es además el Jefe del Grupo de Política Antártica) ${ }^{40}$ en 1975. En ellos se afirma la necesidad de proteger los "derechos e intereses de los EE. UU.; la libertad de exploración y de investigación científica; el libre acceso al desarrollo (entendido como "uso") de los recursos naturales y el establecimiento de reglas no preferenciales para las actividades a realizar con este objeto, así como la conveniencia de contar con un sistema administrativo ordenado para el área ${ }^{41}$. Sus líneas principales vuelven a ser corroboradas en 1979 por las declaraciones de la delegación norteamericana a la 10a Reunión Consultiva del $\mathrm{TA}^{42}$.

Se halían así enunciados los objetivos esenciales. Se desea tener libertad de movimiento en toda el área del Tratado para continuar con la exploración científica, ahora orientada ya hacia la futura explotación comercial. Esta debe basarse en principios que defiendan la igualdad formal (a todos la misma oportunidad) y sentar las bases para un mecanismo administrativo común que ordene las actividades.

Se pretende alcanzar un régimen de explotación mineral dentro del Tratado o por otros acuerdos a él vinculados. Pero, zqué sucedería si por oposición de la URss, de los países con reclamos o por otros factores de este tipo ello no fuera posible? Si se acude al más cercano antecedente -el conflicto sobre el régimen de explotación de los espacios oceánicos más allá de las jurisdicciones nacionales- surge que: a) EE. UU. consideró seriamente (y se exploró su viabilidad con distintos países) la posibilidad de realizar un "minitratado" entre las potencias industrializadas y algunas "potencias emergentes" (Ej.: Brasil) para explotar los recursos fuera del ámbito de las negociaciones de la $\mathrm{ONu}^{43}$; b) se estimó posible que entre las medidas de oposición que surgirían, existiria "el ejercicio de bajos niveles de violencia" 44 . Ante ello, se estimó

39Hearings, us, 1975, p. 30.

${ }^{40}$ El Grupo de Política Antártica (GPA), tiene a su cargo la coordinación y liderazgo de la totalidad de las políticas a desarrollar por las diferentes agencias participantes en actividades antárticas de los EE. UU. (Ver: Circular N.A.-5I, revised. Executive Office of the President, Tashington, DC, August 4,.1971).

41Ver Hearings, Us, $1975, \mathrm{p}, 5$.

42“Press Release 224", September 14, 1979, Department of State Bulletin, November 1979, pp. 21-22.

${ }^{* 3}$ Morris, M.: "Brazil at the Third United Nations Conference of the Law of the Sea", Ocean Development and International Law, Vol. 7, Nos 1-2, 1979, p. 171 .

"Deep Seabed Minerals; Resources, Diplomacy, and Strategic Interest, Subcommittee on International Organizations of the Committee on International 
Cuadro 18

ALGUNOS DATOS SOBRE PESGA DEL KRILL POR MMEMBROS DEL TA (en toneladas métricas)

\begin{tabular}{lrr}
\hline Pais & 1976 & 1977 \\
& & \\
URSs & - & 105.049 \\
Polonia & 21 & 6.966 \\
Japón & 2.226 & 10.517 \\
\hline
\end{tabular}

FUENTE: Estadisticas varias, Fao y L. Kimball, "Exploración y explotación...", obr. cit. .

conveniente que en el caso de ser necesaria la defensa de las operaciones comerciales para la explotación de los recursos mineros en el lecho océanico, se acudiría a "... vincular a esas operaciones al continuum de la disuasión militar mediante declaraciones militares y demostraciones de fuerza, que puedan ser efectivas contra las amenazas de una sola nación" 45 . Si lo que se debía enfrentar era un esfuerzo conjunto del Tercer Mundo, lo más conveniente sería "la negociación de un acuerdo de defensa entre tos países industrializados, similar a los acuerdos de protección de pesquerías en el Mar del Norte"4b. Además, "en adición a las respuestas militares enumeradas, la adopción de medidas políticas y económicas, de carácter positivo y negativo, podrían ser adoptadas para reforzar la disuasión"47.

La alternativa de que se acordara un "minitratado" entre los EE. UU. y otras potencias industrializadas, fuera del ámbito del TA, para la explotación de los minerales antárticos (en particular, el petróleo de la plataforma continental), constituye una posibilidad bien conocida por los expertos y delegados gubernamentales que han asistido a las Reuniones Consultivas, ya que ha sido insinuada en varias oportunidades en conversaciones informales. Si por una parte constituye sin duda un elemento de presión en las negociaciones (que ha tenido su efecto sobre las decisiones de los miembros en desarrollo), no se reduce solamente a ello. Existe ciertamente la posibilidad de un "minitratado", pero su costo político y aún económico puede resultar excesivo, aún suponiendo una actitud pasiva de la uRss (lo cual no puede darse por sentado, sin alto

Relations, House of Representatives, us Government Printing Office, Washington, DC, 1978. (A partir de ahora: Deep Seabed Minerals..., Us. 1978), p. 102.

sorbid, p. 103.

tobid.

"Tbid. 
riesgo), para otro de los actores del sistema mundial: las empresas transnacionales.

\section{Los abjetivos de las ETN}

Cabe preguntarse cuáles son los escenarios más convenientes para las ETN. Siendo su objetivo la obtención dè máximos beneficios, requiere para ello que se satisfagan varias condiciones: entre ellas, el poder trabajar en un clima de estabilidad jurídico-política que garantice la seguridad de sus inversiones.

Obviamente, la situación ideal está dada por el modelo implícito en los principios señalados en la posición norteamericana durante las negociaciones que se efectúan en las Reuniones Consultivas del TA y-con ciertas variaciones- en la de algunos actores europeos (Ej.: Inglaterra). Su expresión anterior se dio en el modelo reclamado por las empresas de minerales pesados en la GONFEMAR ${ }^{48}$ : concesión de licencias exclusivas, respaldadas por el país que la otorga; mínimo pago de derechos de explotación y la mayor libertad posible para controlar todas las etapas del proceso comercial y productivo. Si es necesaria la elaboración de "reglas de juego jurídico-políticas comunes", serán aceptadas en medida proporcional a la satisfacción de estos requerimientos.

¿Qué sucedería si el régimen que los miembros del TA pretenden aplicar es considerado demasiado desventajoso por las ETN? Dada la posibilidad de una gran inestabilidad interna en el subsistema (Ej.: oposición activa de algunos miembros) o de presiones externas generalizadas ( $\mathrm{Ej}_{\mathrm{j}}$ : frente común de los países en desarrollo en contra de un régimen exclusivo de explotación de los recursos antárticos) las ETN deberán evaluar cuidadosamente los costos y beneficios de la alternativa de un acuerdo de pocos miembros seleccionados frente a un régimen más ordenado $y$ estable, si bien menos atractivo.

En el caso de cONFEMAR se pasó gradualmente de la posición inicial (solicitar al Gobierno de los EE. vu. que negocie derechos de tenencia, continuidad de acceso y beneficios ${ }^{49}$ a la aceptación (si bien a regañadientes) del régimen propuesto para la Autoridad

"Ver Hearings before the Subcommittee on Mines and Mining of the Committee on Interior and Insular Affairs, House of Representatives, 94th Congress, Second Session, Hearings held in May 18, 20 and 24, 1976, us Government Printing Office, Washington, DC, 1976, en particular las partes relacionadas con la presentación de Deepsea Ventures, Inc. (A partir de ahora: Subcommittee on Mines, us, 1976.

${ }^{4}$ Hearings before the Subcommittee on International Organizations of the Committee on International Relations, House of Representatives 95th Congress. First Session us Government Printing Office, Washington DC, 1977. (A partir de ahora: Hearings before the Subcommittee on International Organizations. us. 1977) - pp. 66-67. 
Internacional de los Fondos Marinos ${ }^{50}$; es decir, en principio parece haberse logrado un acomodamiento entre los actores desarrollados y en desarrollo y las ETN. El ejercicio de minimax realizado sugiere que es preferible obtener relativamente menores ventajas a cambio de la seguridad de poder participar bajo condiciones estables. Como dijera el director del Departamento de Recursos Oceánicos de la Kennecott Copper: "Lo peor que puede pasarnos es que el Tratado nos deje fuera del negocio"s1.

yor lo tanto, si bien desde el punto de vista militar es natural hablar de detensa de operaciones comerciales -y para algunos empresarıos, solicitarla- en su conjunto parece que las ETN han perdudo gran parte de su confianza en que el Estado en las potencias industriales pueda cumplir eficientemente esas funciones como antaño 52. Las nuevas estrategias de adaptación de las ETN a las fluidas condiciones internacionales podrían muy bien aconsejar la organización de un acuerdo que satisfaga siquiera mínimamente a Los países con reclamos - en especial, a aquellos en desarrollo- y que prevea asimismo alguna distribución de beneficios para el Tercer Mundo trente a un miniclub exclusivo de países industrializados expuesto a grandes presiones y al posible uso de la violencıa. En todo caso, las opiniones parece que comienzan a dividirse en el sector de las empresas transnacionales ${ }^{53}$.

\section{Los objetivos de la URss}

El éxito de todo intento de articular un régimen de explotación de recursos minerales restringido a los países industrializados exige cuando menos la pasividad soviética. Sin intentar predecir su conducta, la observación de las posiciones adoptadas en las Reuniones Consultivas y de las actividades realizadas en el terreno permiten esbozar algunas orientaciones.

Mientras ha expresado su apoyo a una moratoria para la exploración y explotación comercial, la uRss demuestra en la práctica su interés por incrementar sus exploraciones de minerales e hidrocarburos. Sus científicos y técnicos trabajan en el Mar de Ross y la Península Antártica, zonas potencialmente ricas en petróleo y gas ${ }^{54}$

5oVer texto del Docto. oNU: A/Conf. 62/WP. 10/Rev. 1, 28 abril 1979.

"Hearings before the Subcommittee on. International Organizations, us 1977, p. 67.

serbid.

${ }^{6}$ Para un análisis de la evolución del pensamiento de las empresas petroleras sobre este tema, ver las revistas Offshire, Ocean Industry, Ocean World, años 1978-79.

${ }^{51} \mathrm{~L}$. Slevich, Basic Problems of Antartic Exploration (cit. por Auburn, 1977, pp. 148-149) . 
y en estas áreas han instalado varias estaciones científicas ${ }^{55}$. Otra zona de interés para la Unión Soviética es la costa del Mar de Wedell, al sur de la Península Antártica ${ }^{56}$. Esta área promete ser un valioso yacimiento de petróleo y gas. Además, cierta zona de las montañas Pensacola (Dufek) ha sido considerada rica en minerales por soviéticos y norteamericanos ${ }^{57}$.

A lo largo de la década del setenta, la disposición de las nuevas bases de la uRss van conformando un círculo que rodea al continente antártico ${ }^{58}$, combinando un criterio económico (ubicación en función de la exploración de los recursos) con uno geopolítico (localización de estaciones soviéticas en la mayor parte de los territorios antárticos reclamados, mientras nuevas bases se construyen en el sector no reclamado, donde hasta ahora habían actuado prácticamente sólo los EE. UU.).

Estas actividades plantean: 1) Una implícita, pero efectiva capacidad de veto sobre cualquier intento de efectivización de reclamos territoriales (o al menos, la necesidad de negociar sus términos con la URss); 2) asegurarse el acceso selectivo y la participación futura de la explotación de los recursos en todas las áreas antárticas; 3) establecer "contacto estratégico" con lOS EE. UU., de carácter disuasivo (al establecer bases en las zonas adonde se halla la otra superpotencia).

Las "áreas de influencia" oceánicas de la Antártida en el Atlántico Sur y la zona de los accesos Pacífico-Atlántico y Atlántico-Indico (al igual que el flanco oriental de este último) incrementan progresivamente su importancia estratégica para los EE. UU. y la URss., así como naturalmente, para los países marítimos del Cono Sur latinoamericano ${ }^{59}$. En el terreno económico, la uRss pesca intensamente frente a la costa africana y se prepara para una explotación intensiva del krill en las aguas subantárticas. El interés por el krill resulta más importante para los soviéticos que para los norteamericanos, que aún no han desarrollado su capacidad de explotación de ese recurso.

Teniendo en cuenta la situación de la subregión, las capacidades de ambas fuerzas navales y sus necesidades en otras zonas del

"La principal de ellas es "Druzhnaya" (77034' Sur; $40^{\circ} 3{ }^{\prime} 0$ Oeste, en la barrera de Filchner. Instalada en 1976, cerca de donde se hallaba la base argentina "Gral. Belgrano".

60uSA Geological Survey y Slevich, (cit. por Auburn, 1977, p. 149).

${ }^{67}$ uSA. Geological Survey y Slevich, (cit. por Auburn, 1977, p. 149).

sAuburn, 1977, ibid.

${ }^{60}$ Ver las revistas argentinas Estrategia, IAEERT, Bs. As., especialmente Nos 43-44, 1977 y Geopolitica, IDEG, Bs. Aires, y los libros: La Antártida: Un espacio geopolitico, Bs. Aires. Millia, F., Editor, Pleamar, 1979; y Geopolitica y Estrategia del..., op. cit.; la revista uruguaya Geopolitica, IUEG, Montevideo, y la revista Geosur (órgano de la Asociación Sudamericana de Estudios Geopolíticos e Internacionales, año 1979). 
mundo, que no les permite una presencia significativa en la zona subantártica sin debilitar sus compromisos con clientes locales y los requerimientos de equilibrio bélico en otros mares, no parece previsible esperar un incremento importante de fuerzas en esta parte del planeta (salvo casos de profunda alteración del equilibrio estratégico, ya mencionados).

Tanto a los EE. UU. como a la URSs les conviene mantener a la Antártida no militarizada, conservando este aspecto de la detente.

Por su parte los actores europeos industrializados que forman parte en el juego estratégico de seguridad marítima en esta zona excepto quizás, en ciertas ex áreas de influencia (U. K., en los conos sur africano y latinoamericano) en casos de grave riesgo ( $\mathrm{Ej}$. : ataque a las islas Faulkland o a la República Sudafricana). Los esfuerzos europeos se concentran en la exploración de los recursos naturales, como parece demostrarlo la preparación de una expedición antártica europea que contaría con la participación de diez. países de ese continente ${ }^{80}$. Los británicos por su parte han desarrollado investigaciones geológicas en prospección de minerales a lo largo de una extensa faja antártica durante 197961.

VII. LOS INTERESES DE LOS PAÍSES LATINOAMERIGANOS MIEMMBROS DEL TA Y SU INSERGIÓN EN EL SISTEMA INTERNACIONAL

\section{Algunos aspectos generales}

Dadas las características de los modelos políticos y económicos vigentes en Argentina, Chile y Brasil ( $y$ en un potencial candidato a adherir al Tratado, Uruguay) -orientaciones consideradas por los grupos en el poder como defensoras del "interés nacional" que interactúan con políticas económicas neoliberales ${ }^{22}$ - el modo de inserción de estos países en el sistema económico mundial resulta una fórmula mixta. Ella incorpora en grados variables elementos del Laissez Faire, la búsqueda de una integración plena de sus economías al sistema capitalista occidental, y del modelo reformista del Nuevo Orden Económico Mundial (NOEI) Ej.: propuestas de la Carta de Deberes y Derechos de los Estados). Ninguno de estos

${ }^{004}$ A proposed Antartic European Expedition" Antartic Journal, us Vol. viII, No I, Jan-Febr. 1973. 1979.

er"Cold fronts ahead for antartic research" New Scientist, N.Y., 25 October

:Las posiciones a adoptar por los gobiernos de los estados miembros del TA frente a los problemas de exploración y explotación de los recursos son el resultado del producto de las interacciones conflictivas o competitivas entre los intereses polfticos, económicos, cientifico-tecnológicos y de seguridad de los grupos hegemónicos internos y de sus vinculaciones transnacionales. 
actores latinoamericanos apoya la tercera alternativa, que consistiría en una "desvinculación" del sistema mundial63.

Es importante destacar que gran parte de los puntos fundamentales de la propuesta reformista realizada por los países en desarrollo en pos de un NOEI - Transferencia y generación de tecnología; soberanía sobre los recursos naturales; conducta y rol de las empresas transnacionales, etc.- adquieren roles protagónicos como dinamizadores o apaciguadores de los conflictos en el contexto de los futuros acuerdos antárticos sobre explotación de los recursos vivos y minerales.

¿Qué implicancias presentan estas formas de inserción en el sistema mundial con respecto a Ias orientaciones básicas de la conducta a desarrollar por los actores en el marco antártico?

En los casos de Argentina y Chile, las características neoliberales de sus modelos y lo limitado de sus recursos financieros, científicos y tecnológicos favorece en principio la aceptación de acuerdos, con otros estados y con las ETN, que permitan mantener las formas de la soberanía jurídica junto a cierto beneficio económico. No obstante, las constantes geopolíticas propias de valores nacionalistas (Ej.: el compromiso asumido con la defensa de un territorio que se considera nacional) que han mantenido gran continuidad aún bajo gobiernos de distinto signo político, introduce una componente reformista en su estrategia. Ello les permite en grado variable, articular acuerdos implícitos o explícitos con actores de distinto signo ideológico, en defensa de sus posiciones en las negociaciones que realizan las Partes Consultivas del Tratado o para incrementar su capacidad individual de exploración y explotación de los recursos.

Así, tanto Argentina como Ghile han aprovechado la posición de la URss en favor de una moratoria con respecto a la explotación de los recursos minerales para intentar demorar el tratamiento y la adopción de decisiones sobre el tema ${ }^{64}$. Ambos países han buscado y obtenido el apoyo del Tercer Mundo (con algunas excep-

${ }^{a 3} \mathrm{En}$ el contexto de las distintas propuestas para el NOEI se presentan dos modelos de desvinculación: a) el apoyado por los páses más radicales del Tercer Mundo, que consideran que sólo un esfuerzo colectivo, basado en el apoyo horizontal mutuo puede incrementar sus posibilidades de un desarrollo más autonómico y b) el $\mathrm{N}-\mathrm{N}$, propuesto por los grupos más conservadores de los países desarrollados. En síntesis, se sugiere concentrar el esfuerzo cooperativo en las naciones industrializadas, aprovechando sus avances cientifico-tecnológicos para obtener una mayor independencia de los paises del Tercer Mundo en términos de aprovisionamiento de energla y materias primas.

Ver: Cox, R. "Ideologies and the New International Economic Order", International Organization, No 2, 1979, y Moneta, C. "El uso de los modelos de simulación global como instrumento político en el sistema mundial "Estudios del Tercer Mundo", ceestM, Vol. I No 4, México, 1978.

ofver: Moneta, C. "La Antártida Argentina anțe...", art. cit.; Antartic Re" sources, op. cit. 
ciones) para la posición que mantienen en el seno del $\mathrm{TA}$ como países reclamantes. En particular, Argentina utilizó su carácter de miembro de varias agrupaciones de los países en desarrollo para lograr que fuera condenada la ocupación inglesa de las Islas Malvinas ${ }^{65}$.

Chile, por su parte, inició en 1978 conversaciones con China Popular para desarrollar proyectos conjuntos de investigación científica en la Antártida que comprenden a los recursos naturales ${ }^{66}$. Se prevé, inclusive, la posibilidad de organizar una corporación chino-chilena para eventual explotación de los recursos ${ }^{67}$.

Estas aperturas ideológicamente heterodoxas no tienen aún apropiado equivalente cuando se trata de diseñar políticas cooperativas de esta magnitud para la exploración y explotación con actores de rango similar con los cuales se está en situación de conflicto en otras áreas (Ej.: Argentina y Chile) o con otros actores en desarrollo (Ej.: países regionales o extrarregionales que no pertenezcan al Tratado) ${ }^{68}$. Sin embargo, debe destacarse que la colaboración chileno-argentina frente a actores externos continuó -si bien muy debilitada- aún durante los momentos más graves del conflicto del Beagle.

Esta cooperación aún no ha comenzado a explotar las inmensas posibilidades que se le presentan a estos países si se deciden a actuar juntos en el marco interno de su sector Antártico. La suma de sus capacidades financieras, científicas y tecnológicas, unida a su ventajosa posición geográfica, les otorgaría un gran incremento de su capacidad de negociación frente a otros actores, permitiéndoles desarrollar políticas más autónomas y efectivas en el campo de la prospección minera y de hidrocarburos, así como en la explotación del krill. No obstante, hasta el presente, ambos estados han acudido a empresas transnacionales y países industrializados en forma individual $y$ competitiva. Así, por ejemplo, Chile desarrolla un enérgico programa de pesca, utilización y análisis de mercado del krill y otras especies, habiendo establecido joint ventures con Gorea del Sur, España, Taiwán, Alemania Federal, Francia y China

${ }^{a}$ Si bien las Islas Malvinas (Faulkland) no se hallan comprendidas dentro de los límites del TA, la resolución del problema de posición de estas islas afecta en sus aspectos políticos a los conflictos de reclamo sobre sectores antárticos superpuestos entre Argentina e Inglaterra. Argentina ha logrado que el tema de las islas figure en varias Declaraciones de los pafses no alineados, así como en otros foros económicos y políticos del Tercer Mundo.

${ }^{8} \mathrm{~L}$ a Prensa, Bs. Aires, 13/11/1978.

${ }^{*} \mathrm{La}$ Nación, Bs. Aires. 10-6-79.

"Existen sin embargo propuestas "heterodoxas" que se apartan de las corrientes tradicionales, intentando analizar nuevas alternativas en este terreno. Ver por ejemplo: Palermo, A. "China, Chile y algunas otras cuestiones antárticas", Geopolítica, IDEG, Bs. Aires, 13-14, 1979; Moneta, C. "Los problemas antárticos en la década del 80", ciclo de conferencias, ceINAR, Bs. Aires, 1974; 1975. 
Popular. Argentina, que se halla más atrasada en este aspecto, vr que previamente había asignado muy poco interés a la pesca austral, realiza su programa mediante acuerdos con Japón, Corea del Sur, Alemania Federal y España69. De llegarse a un acuerdo por el Beagle, esta situación puede cambiar en el futuro, ya que existe cierta conciencia en ambos países de los costos políticos y económicos que significa el mantenimiento de orientaciones conflictivas de carácter geopolítico en gran medida decimonónicas, inadecuadas en escala y perspectiva a los desafíos que ambos enfrentarán en las próximas décadas.

EI caso de Brasil es cualitativamente distinto, ya que recientemente ${ }^{70}$ despierta su interés por la Antártida, en virtud de la nueva dimensión estratégica a que lo conduce su estatus de potencia emergente y con la esperanza de poder participar en el aprovechamiento de los recursos naturales (particularmente los energéticos, ya que el país tiene un $80 \%$ de provisión externa de petróleo). Sus Ifderes, por lo tanto, poseen un grado de flexibilidad mayor en cuanto a objetivos y políticas.

Habiendo adherido al TA en 197671 , no poseyendo por el momento posibilidades -en virtud de las limitaciones que impone el Tratado- de realizar oficialmente reclamaciones territoriales; consciente del peso de las fuerzas que orientan de facto al proceso antártico hacia el condominio colectivo entre un número limitado de miembros; poseedor de excelentes vinculaciones económicas con Ios actores industrializados y en pleno desarrollo de un potencial industrial y tecnológico que lo coloca como uno de los primeros países no centrales capaz de desarrollar cierta capacidad autónoma de explotación minera de los océanos72 Brasil tiene mucho que ganar y nada que perder por su vinculación al Tratado y a Ios futuros acuerdos que emanen de él.

Inclusive las alternativas de Brasil no se limitan a confiar en sus propias fuerzas, ya que puede (como cualquiera de los otros miembros) servir de vehículo para que otros actores (transnacionales o nacionales) accedan indirectamente al continente antártico. Durante la primera reunión informal de expertos que se realizara en Noruega, en 1973, para analizar los problemas relativos a la exploración y posible explotación de recursos minerales en la

"Ver: L. Kimball, "Exploración y explotación del krill...", op. cit.

${ }^{70}$ Sobre las circunstancias de la adhesión brasileña al $\mathrm{TA}$, ver: Greño Velasco, J. E., "La adhesión de Brasil al Tratado Antártico", Revista de Política Internacional, Inst. de Est. Políticos, No 146, Madrid, 1976.

rVer: Morris, M., "Brazil at the Third United Nations Conference on the Law of the Sea", Ocean Development and International Law, Vol. 7, Nos I y 2. New York, 1979.

${ }^{72}$ Antartic Resources..., op. cit. 
Antártida ${ }^{73}$, se planteó la posibilidad de que empresas transnacionales pudieran intentar realizar operaciones a través de las naciones sede de sus matrices o utilizando subsidiarias, ubicadas en otros estado-naciones que participarán en el Tratado.

El mismo recurso podría ser empleado por un actor nacional o supranacional externo al $\mathrm{TA}$ mediante acuerdos con otro estado que si fuera miembro. Según información de carácter público, que aún no pudo ser confirmada, la Comunidad Económica Europea y Brasil sostendrán conversaciones a los efectos de estudiar la posibilidad de que la CEE provea a ese país de asistencia tecnológica y financiera para que lleve adelante la exploración de los recursos antárticos 74 .

Por su parte, Uruguay ha manifestado su interés en participar en las actividades científicas en la Antártida, si bien no ha realizado aún ningún reclamo territorial o solicitado adherirse al Tratado ${ }^{75}$. Dada su condición de país de menor desarrollo relativo, la estrategia más viable parece consistir en llegar a un acuerdo con Argentina y Brasil (o con uno de ellos), que le permita realizar cierta actividad científica en el terreno, así como asociarse con ellos en el futuro, cuando se arribe a la fase de explotación. Una segunda alternativa - que no ofrece muchas chances- es la de intentar convertirse en país anfitrión de una empresa transnacional.

Desde el punto de vista de la seguridad, Argentina y Chile difieren naturalmente en sus objetivos con respecto a las superpotencias y los restantes actores que no reconocen sus reclamos territoriales. Su propósito principal es apoyar mediante la acción diplomática, científico-técnica y la presencia efectiva en sus sectores, el ejercicio de su soberanía.

En el caso de llegarse a un acuerdo mínimamente satisfactorio entre los miembros del TA, se tratará de obtener las mejores condiciones posibles frente a los otros actores en términos de asegurar su participación efectiva en las decisiones del conjunto, obtener los máximos beneficios económicos y salvaguardar en alguna medida las formas de una soberanía. Frente a los no-miembros del Tratado tenderán a coincidir con el resto de los participantes en el mismo, en una política común de mantener un régimen exclusivo para la Antártida.

aver: Antartic Resources..., op. cit., pp. L-3; L-1I-L13 y Moneta G., "Antártida Argentina. Los problemas...", art. cit,, pp. 25-26.

${ }^{7 t}$ Información de prensa transmitida por radios de la Ciudad de México, México, 4 de diciembre de 1979.

${ }^{75}$ Este pais posee un Instituto Antártico, oficializãdo en 1975 y una Comisión de Estudios Antárticos, organizada en 1970 bajo la dependencia de la Cancillería, con el objeto de asesorar al Gobierno sobre actividades en la Antártida. Además, se ha anunciado en varias oportunidades la intención de enviar una expedición cientifica. 
Sin embargo, de no alcanzarse un entendimiento, Argentina y Chile pueden verse tentados de acudir a medios no pacíficos para preservar siquiera parte de sus derechos. Si bien se trata indudablemente de un último recurso, su utilización a través de una "diplomacia militar" no es descartable, ya que ha sido utilizada en varias oportunidades entre ellos mismos ( $\mathrm{Ej} .:$ actos de ocupación de islas antárticas y realización de ejercicios militares, período 1940-50) y frente a Gran Bretaña (1943; 1952; 1953, etc.) ${ }^{76}$. El último incidente de esta naturaleza fue en 1976, cuando un destructor argentino hizo fuego contra una nave de investigación científica inglesa que se hallaba realizando estudios geológicos relacionados con la existencia de hidrocarburos en la plataforma continental que rodea a las Islas Malvinas (Faulkland), sobre las cuales Argentina reclama su soberanía.

En un contexto mayor, la observación de los incidentes a que dio lugar el uso de "la presencia naval" a partir de la Segunda Guerra Mundial, demuestra que en numerosas oportunidades ( $\mathrm{Ej}_{\mathrm{j}}$.: Gran Bretaña con Islandia; Ecuador y Perú con los Ee. UU.; Argentina con Polonia y la URss), los países medianos $-y$ aún pequeños- han utilizado su limitado poder naval en defensa de sus territorios y recursos naturales. De igual manera, estos casos señalan que las grandes potencias demostraron en esas oportunidades cierta reticencia en replicar de la misma manera, dados los costos políticos inherentes. En general se contestó utilizando el amplio espectro de recursos de coerción económica a su disposición ( $\mathrm{E}_{\mathrm{j}}$.: restricciones a la asistencia financiera, comercio, etc.).

\section{América Latina ante el subsistema antártico}

Los cambios producidos en el sistema internacional en la década del setenta han contribuido -junto con factores endógenos de carácter nacional y regional- a modificar sustancialmente las posibilidades y exigencias que deben afrontar las naciones latinoamericanas. Aquellos estados dotados de potencial viabilidad individual (México, Argentina, Brasil, Venezuela) comienzan a trascender los Í́mites del marco regional, proyectándose a través de los planos ideológico, político, económico y cultural a otras regiones y sectores del accionar internacional.

Así, por ejemplo, México proyecta su influencia político-ideológica a nivel mundial $y$, particularmente, en el mundo en desarroIIo a través de la Carta de Deberes y Derechos de los Estados, mientras que su área de influencia económica alcanza al Caribe y en un plano sectorial dependerá de la orientación que adopte la política petrolera.

${ }^{7}$ Estos incidentes se produjeron entre Argentina y Gran Bretaña. 
De igual manera, Cuba y Brasil se proyectan bajo distintos proyectos político-económicos al Africa y este último país planea actualmente su presencia en la Antártida. Además, en virtud de la argumentación jurídica que elaboró para justificar un eventual reclamo territorial -la teoría de la "defrontaçao" (basada en la Teoría de Sectores) - Brasil abre conscientemente las puertas para aue otros estados de América del Sur (Ej.: Uruguay, Perú, Ecuador) planteen también sus reclamos ${ }^{77}$.

En suma, nos hallamos ante un cuadro de situación muy dinámico, caracterizado por la quiebra de los límites regionales para la acción de algunos estados latinoamericanos y una creciente interdependencia sectorial y funcional, en virtud de modificaciones del sistema mundial en áreas totalmente nuevas para algunos de ellos.

En este contexto, ¿cuáles son las potenciales interacciones del subsistema antártico con el subsistema latinoamericano y el sistema mundial que pueden afectar los intereses de los actores mayores (y de algunos medianos) del subsistema latinoamericano? Pueden ya señalarse en principio algunas de las áreas y temas que resultarán de diferente grado de interés para ellos.

Como ya se ha comentado, la resolución de los problemas antárticos constituye un "banco de prueba" para observar la evolución del nuevo régimen internacional. La Antártida dará en la década del ochenta un ejemplo de la orientación que adoptarán los conflictos "Países desarrollados v/s Países en desarrollo" y sus alternativas de solución en el caso de la exploración y explotación de recursos naturales cuya jurisdicción se halla en discusión. Como impulsora del NOEI, América Latina seguirá con interés las modalidades que adopte su aplicación en la Antártida.

Los potenciales conflictos a presentarse entre la Autoridad Internacional que administre Ios recursos oceánicos situados más allá de las jurisdicciones nacionales (supuesta la aprobación de los resultados de la Conferencia onu sobre el Derecho del Mar) y los miembros del Tratado Antártico resultan del interés de América Latina, ya que afectarán un extenso espacio oceánico dotado de ri$\cos$ recursos renovables y no renovables relativamente cercanos a parte de sus costas. Las modalidades de distribución de los beneficios derivados de su explotación variarán significativamente, en función de los desacuerdos o acuerdos a lograr. De igual manera, los principios y regulaciones del NDM a los cuales América Latina contribuyó positivamente a formar, lograrán mayor o menor aplicación en este caso.

${ }^{7 \pi} \mathrm{La}$ necesidad de plantear los derechos de Perú y Ecuador a un sector antártico ya han sido presentados a la opinión pública por geopolíticos de dichos países. 


\section{Situación energética mundial y regional}

Dadas las dimensiones potenciales de los depósitos offshore de petróleo y gas en la Antártida, el hecho de confirmar su riqueza y entrar gradualmente en producción (ambos pueden ser incluidos en el horizonte de capacidades tecnológicas de la década del ochenta-noventa) modificará sensiblemente la situación política y económica de los países exportadores de petróleo y de aquellos estados $y$ actores externos (Ej.: Estados Transnacionales) miembros o no miembros del TA, que participen en su explotación.

Así las potencias industrializadas -en particular los EE. UU.tendrán acceso directa o indirectamente a nuevas fuentes de energía en mayores y mejores condiciones de control. Los países exportadores de petróleo deberán tener muy en cuenta este hecho, ya que podría modificar su poder de negociación frente a los países industrializados importadores de petróleo.

En el contexto regional, Argentina, Ghile y muy posiblemente Brasil obtendrán nuevas fuentes de producción energética, situación que modificará sensiblemente su viabilidad económica y las políticas a adoptar con respecto al problema energético a nivel internacional y regional. Argentina y Ghile podrán convertirse en exportadores (Argentina ya se halla al borde de hacerlo en el presente, sin contar aún con estos recursos, pero Chile aún debe satisfacer casi el $50 \%$ de su demanda interna) y Brasil aliviará sensiblemente su crítica insuficiencia energética. Con nuevos recursos económicos a su disposición es dable expresar un aumento del crecimiento económico de estos países y de su acción política regional.

México y Venezuela podrían tener en consecuencia dos o quizás tres nuevos actores significativos en el campo energético regional, animados además (Argentina y Brasil) de capacidad tecnológica nuclear relativamente avanzada para la generación energética. La actual distribución de poder (considerada en el plano de la posesión de recursos críticos y capacidad económica para proyectarse externamente) en el marco regional se vería alterada.

Lo expuesto en los puntos anteriores señala que para algunos países de América Latina serán de gran interés los resultados a que den lugar la resolución o agravamiento de los conflictos del subsistema antártico. No debe descartarse que los países latinoamericanos miembros del rA soliciten apoyo político para fortalecer sus posiciones (frente a competidores de la región o actores externos miembros del Tratado) o por el contrario, si la concepción cooperativa se afirma, apoyo económico para participar técnica y financieramente en la exploración y explotación de los re. cursos energéticos. 


\section{LOS FAGTORES CONDIGIONANTES DE LA COOPERAGIÓN Y EL CONFLICTO EN LA TA: LA VIABILIDAD TEGNOLÓGICA}

Las consideraciones realizadas hasta ese momento dependen esencialmente de la variable tecnológica. Los supuestos -hasta ahora implícitos- de este trabajo en el campo tecnológico parten de dar como posible un avance tal en los sistemas y medios de perforación petrolera offshore, exploración comercial, producción, almacenamiento, transporte y control de contaminación que hagan posible la explotación en el margen de una a dos décadas.

Las opiniones en este terreno resultan altamente conflictivas. Según el informe de un grupo de expertos en exploración y explotación minera convocado por los miembros del $\mathrm{TA}^{78}$ en 1977, existe ya la tecnología para la perforación (desde estructuras móviles) hasta profundidades de más de $1.000 \mathrm{mts}$. en áreas libres de grandes témpanos, situación que no es fácil de hallar/en la Antártida. La tecnología actual parece no augurar avances revolucionarios en unidades de superficie ${ }^{79}$. Sin embargo éstos se están dando ja en el diseño avanzado de unidades submarinas, capaces de evitar los problemas creados por los témpanos. Se espera que esta tecnología sea utilizable en uno o dos lustros ${ }^{80}$.

Con respecto a producción, también es en el sector submarino a donde se esperan los mayores avances 81 . En cuanto al transporte, enormes adelantos se han logrado en la explotación y transporte (por barcos y oleoductos) del petróleo obtenido en zonas árti$\mathrm{Cas}^{82}$. Estas innovaciones (Ej.: buques especialmente acondicionados, de gran maniobrabilidad y resistencia, acompañados de rompehielos) ${ }^{83}$ son fácilmente transferibles a la Antártida. Asimismo se registran cambios cualitativos esenciales en los sistemas de transporte terrestre, mediante nuevos vehículos que utilizan el colchón de aire s4 $^{8}$ se intenta coordinar un sistema de "ómnibus aéreo" que atraviese la Antártida ${ }^{85}$. Por último, el almacenamiento ya presenta modelos de tanques sumergidos (utilizados ahora en Me-

${ }^{78}$ (EAMREA) "Group of Specialists on the Environmental Impact Assesment of Mineral Exploration and Exploitation in Antarctica", sCAR, 1977. Ver también: World Oil, usA, July 1979, pp. 79, 57-58.

Tribid, p. 18.

solbid, p. 5.

"11Ver: "Industry crushes", "Frozen obstacles", OFFshore, February 1979, p. 163; "Polar Gas Pipeline", TransCanada Pipelines, November 1972; ofrshore; February 1979, p. 168; NY Times; January 15, 1980, Section C., p. C3.

${ }^{32}$ Ver: OFFSHORE, February 1979, "Industry crushes...", art, cit.

sabid, pp. I63-64.

${ }^{84}$ Ibid, Pp. 162-163.

ss"Airbus: an international air transportation system for Antartica", Antartic Journal, Vol. vw, No 1, Jan-Feb. 1973. 
dio Oriente), que con pocas modificaciones se adaptarán al rígido ambiente antártico.

En resumen, los inconvenientes de carácter tecnológico resultan superables en un plazo no muy largo (¿una década?) si se invierten los recursos necesarios para investigación. La explotación comercial del petróleo antártico depende en mayor grado de los precios internacionales del recurso y sus costos de explotación. Estos últimos resultan indudablemente superiores a los de otras zonas más accesibles y fáciles, pero el costo es también función -entre otros factores- de los adelantos tecnológicos y éstos avanzan rápidamente. En cuanto al precio del petróleo, su crecimiento supera todos los cálculos de los expertos. Si en la situación internacional se continúan generando factores conflictivos - particularmente alrededor del Golfo Pérsico- el petróleo puede llegar a merecer un precio "político" por parte de los EE. UU. y de otros actores industrializados. Es decir, es dable esperar que exista una mayor voluntad política en invertir en áreas más "seguras" desde el punto de vista geopolítico. Entre ellas, si bien no en el primer lugar, se haIlará la Antártida.

Supuesta la existencia de dicha voluntad política y ya adoptada -como lo demuestran el número de solicitudes de exploración comercial de hidrocarburos realizadas por empresas privadas ante varios países industrializados- una decisión básica de invertir en investigación y desarrollo por parte de las grandes empresas multinacionales líderes en este campo, los obstáculos financiero-tecnológicos podrán ser superados; sólo será cuestión de tiempo. La orientación favorable de Ias ETN se debe en parte a que acceder a la Antártida constituye, desde el punto de vista tecnológico, la lógica continuidad de un esfuerzo de trabajo en áreas inhóspitas que demandan nueva tecnología iniciado en la explotación del Mar del Norte. Se extiende un paso más allá en su exigencia en la actual fase de exploración y explotación de la zona ártica del globo y culmina en la Antártida. Después de todo se trata básicamente de una transferencia de lo aprendido y actuado en el Artico y en otras áreas a un nuevo terreno, para el cual parte de la tecnología necesaria ya existe o está por lograrse.

Ahora bien, si se analiza quiénes son los poseedores de las imprescindibles innovaciones tecnológicas, esenciales para emprender una actividad efectiva de exploración y explotación comercial de hidrocarburos, se llega rápidamente a la conclusión de que un grupo relativamente reducido de ETN (Ej.: Exxon; Shell) y algunos centros de investigación de los pafses desarrollados poseen su control. En consecuencia, los países en desarrollo miembros del $\mathrm{TA}-\mathrm{Y}$ aquellos que pudieran incorporarse en el futuro a los acuerdos a que eventualmente se arribe en materia de explotación- dependerán en gran medida de estas empresas para tornar viables sus 
propios programas de explotación. Las situaciones - ya bien conocidas- que se han presentado en las modalidades de este tipo de relaciones en el pasado no constituyen precisamente un precedente alentador. Posiciones equivalentes a las presentadas en el NDM con respecto a la explotación de nódulos minerales en alta mar tenderán a repetirse ( $\mathrm{Ej} .:$ antagónicas propuestas sobre el modelo de la Autoridad, sus funciones, capacidades, etc., vis a vis las ETN presentadas por los países desarrollados y en desarrollo).

No obstante, la experiencia en negociación con las ETN ganada por las naciones en desarrollo puede cambiar en cierto grado una apreciación pesimista sobre sus chances de viabilidad autónoma, si resulta posible incrementar su capacidad de acción a través de una cooperación efectiva en lo político, económico y tecnológico. Ello implica empero voluntad política común (aunque sea en el plano sectorial y funcional), exactitud en la apreciación de límites y oportunidades, sumadas a una gran flexibilidad y pragmatismo en la acción; características que en virtud de los conflictos existentes no serán fácilmente alcanzables. Empero, el camino está abierto para ello. A modo de ejemplo, empresas multinacionales latinoamericanas de exploración y explotación de hidrocarburos pueden ser organizadas alrededor de un eje argentino-chileno, contando con la ineludible participación de Brasil, para actuar en la Antártida. Si bien indudablemente requerirán asistencia tecnológica y financiera externa, las condiciones básicas de negociación habrán cambiado significativamente. De igual manera, la apertura selectiva a esfuerzos compartidos con otros países (que pueden incluir a miembros del TA de carácter "mediano" pero poseedoras de cierto aporte tecnológico, tal el caso de Noruega y naciones de la OPEP y del Tercer Mundo, etc.) puede constituir un medio efectivo para evitar competencias inútiles ( $\mathrm{Ej}$.: surgimiento de nuevos reclamos territoriales en el caso de América Latina) y sumar en cambio el apoyo politico de la comunidad latinoamerzcana y eventualmente de otros del mundo en desarrollo.

Este apoyo será necesario tanto en el caso de que el Tratado se mantenga y sus miembros lleguen a un acuerdo como en la alternativa de que sea imposible conciliar los intereses antagónicos en su seno. Ninguno de los modelos que se han propuesto y discutido muy informalmente hasta el momento como vias de posible solución -Ej.: acuerdos internacionales con participación de las $\mathrm{Na}$ ciones Unidas; reconocimiento de los reclamos territoriales; Sobe; ranía Conjunta (Modelo de Spitsbergen) - releva a Argentina y Chile de sus insuficiencias básicas cuando se intente lidiar en la práctica con la explotación de los recursos, ni anula la necesidad de crear un entorno político-económico favorable. Será precisa- 
mente la nueva conformación del subsistema regional y del régimen mundial que se está desarrollando. la que aconseje dicha estrategia para el bien de ambas naciones, de América Latina y de los países en desarrollo en su conjunto.

\section{B I B L I O G A F I A}

Auburn, F. "Petr. y Gas".: Auburn, ii. "Otfsnore Petróleo y Gas en la Antărtida" en: Geopolitica $y$ Politica de Poder en el Atlántzco Sur, Edip. por C. Moneta, Edit. Pleamar, Bs. Aires, (en preparación). Este trabajo u Auburn se halla publicado como artículo en German Year. book of International Law, Vol. 20, 1977. (El número de página corresponde a la publicación alemana).

Bootr, K., 1979: Booth, K. "The Military implications of the changing Law of the Sea", in Law of the Sea: Neglected Issues, Proceedings Law of the Sea, Twelfth Annual Conference (October, 1978), Ed. by John King Gamble, Univ. of Utrecht, The Hague, Netherland, 1979.

Buzan, B. 1978: Buzan, B. $A$ sea of troubles? Sources of dispute in the New Ocean Regime, Adelphi Papers No 143, spring 1978.

BuzAN, B. 1976: Buzan B., Seabed Politics, Praeger, N. X., 1976.

GUYER, 1977: Guyer, R., "The Antartic System". Collected Gourses of the Hague Academy of Intemational Law, 1973, Vol. I39, Sijthoff, Leyde, 1974.

Hollich, 1974: Hollich, A. "Bureaucrats at Sea. New Era of Ocean Poltics, by Hollich and Osgood, Studies in International Affairs, John Hopkins Univ. Press, 1974.

HANNESSIAN, 1974: Hannessian, J "Overview: Some International Legal Considerations", en Science, Technology and Sovereignty in the Polar Regions, Edited by G. S. Schatz, Antartic Society,
Lexington Books, Mass., 1974.

Follrch, A. 1974: Hollich, A. and Osgood, R. New Era of Ocean Politics. John Hopkins Univ. Press, Baltimore, 1974.

KNIGHT, 1974: Knight, G. "Special domestic interests and United States Policy", in International Relations and the future of the Ocean Space, Univ. of South Carolina Press, Columbia, 1974.

LINDBLom. 1977: Lindblom, C. Politics and Markets. The World's Political and Economic Systems, Basic Books, N. Y., 1977.

LUTTWARK, E. 1974: Luttwark, E. The Political Uses of Naval Power. John Hopkins Univ. Press, Baltimore, 1974.

Mangone, 1978: Mangone, G. Marine Policy for America: The United States at Sea. Lexington. Books, Mass., 1978.

Mennis y Sauvant, 1976: Mennis, B. Y Sauvant, K., 1976, Emerging forms of Transnational Community, Heath and Co., Lexington, Mass., 1976.

Mrghalet, 1976: Michalet, G. Le Capitalisme Mondial, París, P. U. F., 1976.

Morrus, E., 1976: Morris, E. The Russian Naty: Nyth and Reality. Stein and Day, New York, 1976.

MonetA, 1980: Moneta, G. "Aspectos conflictivos de las relaciones afro-latinoamericanas: Ias vinculaciones políticas, económicas y militares de Sudáfrica con los pał́ses del Atlántico sudamericano', en Geopolitica y Politica de Poder en el Atlántico Sur. $\mathrm{Ed}$. Pleamar, Buenos Aires. $\left(\mathrm{E}_{1 \mathrm{i}}\right.$ 
preparación); a publicarse en 1980).

Moneta, 1974-75: Moneta G. "Antártida Argentina: los problemas de 1975-1990". Estrategia, Nis 31-32, Bs. Aires, Nov-Dic. 1974; Ener-Feb. 1975 pp. 4-14.

O'Connor, 1973: O'Connor, The Fiscal Crisis of the State, St. Martin Press, N. Y., 1973.

OsGood, R., 1974: Osgood, R., "U. s. Seventy Interest in Ocean Law", in New Era of Ocean Politics. John Hopkins Univ. Press, Baltimore, 1974.

OsGood, 1974: Osgood, R. "U. S. Security Interest in Ocean Law", in New Era of Ocean Politics, op. cit.
Solude, F., 1979: Sollie, F., "Trends and Prospects for Regimes for Living and Mineral Resources in the Antartic", in Law of the Sea, Neglected Issues, op. cit.

The FridtJor of NAUSEN FoundaTION MEETING ON MiNeral..., 1973:Antartic Resources, Report from the infound meeting of experts. The Fridtjof Nausen Foundation, POLFOGDA, Norway, 30 May-9 June 1973.

VAN EsSEN, 1975-76: Van Essen A., "L'Antartique et la Droit de la Mer". Revue Iranienne des Relations Internationales. Univ. de Teherán, Nìs 5-6, hiver, winter 1975-76. 